\title{
Radiating Benefit of Windbreak and Sand Fixation in the Baijitan Nature Reserve of Lingwu, Ningxia, China
}

\author{
Chao Song ${ }^{1}\left(\mathbb{D}\right.$, Qiyin $\mathrm{u}^{2}{ }^{2}$, Ruixia Wang ${ }^{3}$ and Guofa Cui ${ }^{1, *}$ \\ 1 School of Ecology and Nature Conservation, Beijing Forest University, Beijing 100083, China; \\ songchao@bjfu.edu.cn \\ 2 China National Forestry-Grassland Economics and Development Research Center, Beijing 100714, China; \\ tzey@live.cn \\ 3 Ningxia Lingwu Baijitan National Nature Reserve Administration, Yinchuan 751400, China; bjtwrx@163.com \\ * Correspondence: cuiguofa@bjfu.edu.cn; Tel.: +86-13501036334
}

check for updates

Citation: Song, C.; Yu, Q.; Wang, R.; Cui, G. Radiating Benefit of Windbreak and Sand Fixation in the Baijitan Nature Reserve of Lingwu, Ningxia, China. Sustainability 2021, 13, 3508. https://doi.org/10.3390/su13063508

Academic Editor: Alessandra De Marco

Received: 27 January 2021

Accepted: 16 March 2021

Published: 22 March 2021

Publisher's Note: MDPI stays neutra with regard to jurisdictional claims in published maps and institutional affiliations.

Copyright: (C) 2021 by the authors Licensee MDPI, Basel, Switzerland. This article is an open access article distributed under the terms and conditions of the Creative Commons Attribution (CC BY) license (https:// creativecommons.org/licenses/by/ $4.0 /)$.

\begin{abstract}
Many important ecosystem services show spatial flow characteristics, which are crucial for the study of environmental processes, such as the transformation, correlation, coordination, and management of ecosystem services at different scales. As a result, flow characteristics should be taken into account when it comes to the evaluation of ecosystem services. The study area was the Baijitan Nature Reserve, used to assess the radiating benefits of the windbreak and sand fixation from 2000 to 2019, based on wind erosion loss and sand spatial erosion models. The main results are as follows: Firstly, the fractional vegetation coverage (FVC) clearly increased over the last 20 years and the medium coverage, which accounted for $66.13 \%$, became the main vegetation cover. The wind speed in the reserve dropped gradually as well. Secondly, sand only affected the nature reserve and the surrounding communities. When the wind speed was above a strong breeze $(10.8-13.8 \mathrm{~m} / \mathrm{s})$, coarse silt could affect 26 downwind administrative regions, with an affected area of $2.13 \times 10^{6} \mathrm{~km}^{2}$. Thirdly, the benefits of windbreak and sand fixation varied with the beneficial range, including distance from the Baijitan Nature Reserve and the beneficial area. Dust deposition decreased as the beneficial distance increased. For instance, Shaanxi Province saw the greatest benefit of windbreak and sand fixation, with a dust deposition reduction of $6.87 \times 10^{7} \mathrm{t}\left(1 \mathrm{t}=10^{3} \mathrm{~kg}\right)$, followed by Hubei and Henan Provinces, with reductions of $5.31 \times 10^{7} \mathrm{t}$ and $5.59 \times 10^{7} \mathrm{t}$, respectively. Fourthly, the periodical deposition in administrative regions decreased gradually, as did the different influence ranges. The dust depositions in the five phases of Shaanxi Province were $2.04 \times 10^{7}$, $1.83 \times 10^{7}, 6.63 \times 10^{6}, 4.65 \times 10^{6}$, and $3.48 \times 10^{6} \mathrm{t}$. Fifthly, medium silt, fine silt, and clay silt could easily drift long distances under the influence of sand-driving wind, thus affecting the air quality in downwind administrative regions. Sixthly, the sand source in Baijitan Nature Reserve was an important factor that caused sand-dust weather in downwind areas. The frequency of sand-dust weather was significantly higher in cities near the sand source than in other regions in downwind areas, and the correlations between particle concentrations less than 10 microns in diameter $\left(\mathrm{PM}_{10}\right)$ and the time sequences of sand-driving wind reached significant levels in certain cities. We found that the windbreak and sand fixation in Baijitan Nature Reserve could offer great benefits to the downwind area. Establishing a desert nature reserve could be a great way to promote environmentally sustainable development since it could effectively reduce dust deposition and the frequency of sand-dust weather in downwind areas.
\end{abstract}

Keywords: wind erosion loss model; dust deposition; desert nature reserve; attenuation law; Baijitan Nature Reserve

\section{Introduction}

Ecosystem services are the benefits people obtain from ecosystems, such as the stuff of life, the regulation of the Earth's climate, the filtration of wastes and pollutants, protection 
from extreme weather, and flood, fire, and disease regulation [1]. The benefits that ecosystem services provide are the conditions for all people to lead a decent, healthy, comfortable, and secure life [2]. Scientists around the world have been devoted to ecosystem services on different scales and the creation of systems to evaluate ecosystem services has become the forefront of ecological research [3]. Meanwhile, numerous achievements have been made in some fields such as forest [4], wetland [5,6], desert [7,8], grassland $[9,10]$, ocean $[11,12]$, farmland $[13,14]$, urban [15-18] ecosystems, and nature reserves $[19,20]$.

There are still some ecological issues that need to be identified. For example, how should the spatial flow characteristics of ecosystem services be measured? Some research in recent years has emphasized the importance of ecosystem services and summarized some simple but incomplete approaches to assessing the benefits of ecosystem services. Meanwhile, the spatial flow characteristics of ecosystem services have rarely been studied. The spatial flow characteristics of ecosystem services refer to the process by which the benefits provided by an ecosystem radiate to other areas. For instance, the windbreak and sand fixation effects of desert ecosystems can protect downwind areas from wind erosion. In addition, some regional protected areas that have an essential influence on industrial and agricultural production are easy to neglect when assessing ecosystem service benefits on a large scale. For instance, the Baijitan National Nature Reserve in Lingwu City of Ningxia (hereinafter referred to as the BNR), located at the edge of Mu Us Sandy Land, plays an important role in protecting the Yellow River, maintaining ecological security, and improving the ecological environment around it, while its major ecosystem services, windbreak and sand fixation, can reduce greatly the frequency of sand-dust weather in the downwind area. Since the establishment of the reserve, through years of exploration, desertification prevention and control has been established and the south and west expansion of the $\mathrm{Mu}$ Us Sandy Land has been prevented [21]. Scientific evaluation of the service value of desert ecosystems is of great significance to ecological restoration and reconstruction in arid areas, and also contributes to the sustainable development of the social economy in arid areas [7].

We selected BNR as a case study to evaluate the radiating benefits of windbreak and sand fixation. Here, fractional vegetation coverage (FVC), which can effectively reflect vegetation cover, growth state, biomass, etc., was used to study windbreak and sand fixation as important basic data, and this metric has been widely used in the study of vegetation dynamics [22,23]. For example, it has been used to calculate the sand-fixing function [24], ecosystem service benefit transfer [25], and the response of wind erosion dynamics [26]. The normalized difference vegetation index (NDVI) can effectively indicate the growth status of plants and the spatial distribution density of vegetation, so it is one of the most widely used vegetation indexes to reflect the vegetation coverage in a study area, corresponding to each pixel. In addition to this, we used the dust deposition, calculated by a wind erosion model, as the primary index to measure the benefits of windbreak and sand fixation effects. Recently, researchers have carried out a large number of wind erosion simulation studies in different regions using the Texas Tech Erosion Analysis Model (TEAM) [27], the Wind Erosion Prediction System (WEPS) model [28], the Modified Wind Erosion Equation Model (RWEQ) [29,30], and the Wind Erosion Loss Model [31]. Dong Zhibao's Wind Erosion Loss Model, established on the basis of wind tunnel experiments and field observations, has been applied in arid and semi-arid areas of China in many studies [32-34] and has obtained remarkable results. Similarly, we calculated the dust deposition in downwind areas of the BNR using this model.

Accordingly, it is necessary to study the radiating benefits of ecosystem services in order to provide a theoretical basis for establishing an evaluation system, which can be used to estimate the value of desert ecosystem services in nature reserves.

\section{Materials and Methods}

\subsection{Study Area}

The BNR was designated as a national nature reserve in April 2000. It lies at the edge of the Mu Us desert and the desert area in the eastern part of the Yellow River diversion 
irrigation area in Lingwu City, Ningxia, China (Figure 1), and has a relatively fragile ecological environment. The BNR is situated between $37^{\circ} 49^{\prime} 05^{\prime \prime}$ and $38^{\circ} 20^{\prime} 54^{\prime \prime} \mathrm{N}$ and $106^{\circ} 20^{\prime} 22^{\prime \prime}$ and $106^{\circ} 37^{\prime} 19^{\prime \prime} \mathrm{E}$ and measures $61 \mathrm{~km}$ from north to south and $21 \mathrm{~km}$ from east to west, with a total area of approximately $748.43 \mathrm{~km}^{2}$, which is about a quarter of the size of Lingwu City. The core area of the BNR is $313.18 \mathrm{~km}^{2}$, the buffer area is $186.06 \mathrm{~km}^{2}$ and the experimental area is $249.19 \mathrm{~km}^{2}$. The northern part of the reserve is adjacent to Yinchuan Hedong International Airport, which is $10 \mathrm{~km}$ from Yinchuan City, and the western part of the reserve is adjacent to Qingtongxia City and Wuzhong City. Several national roads and provincial roads pass through BNR, enabling convenient transportation [21].
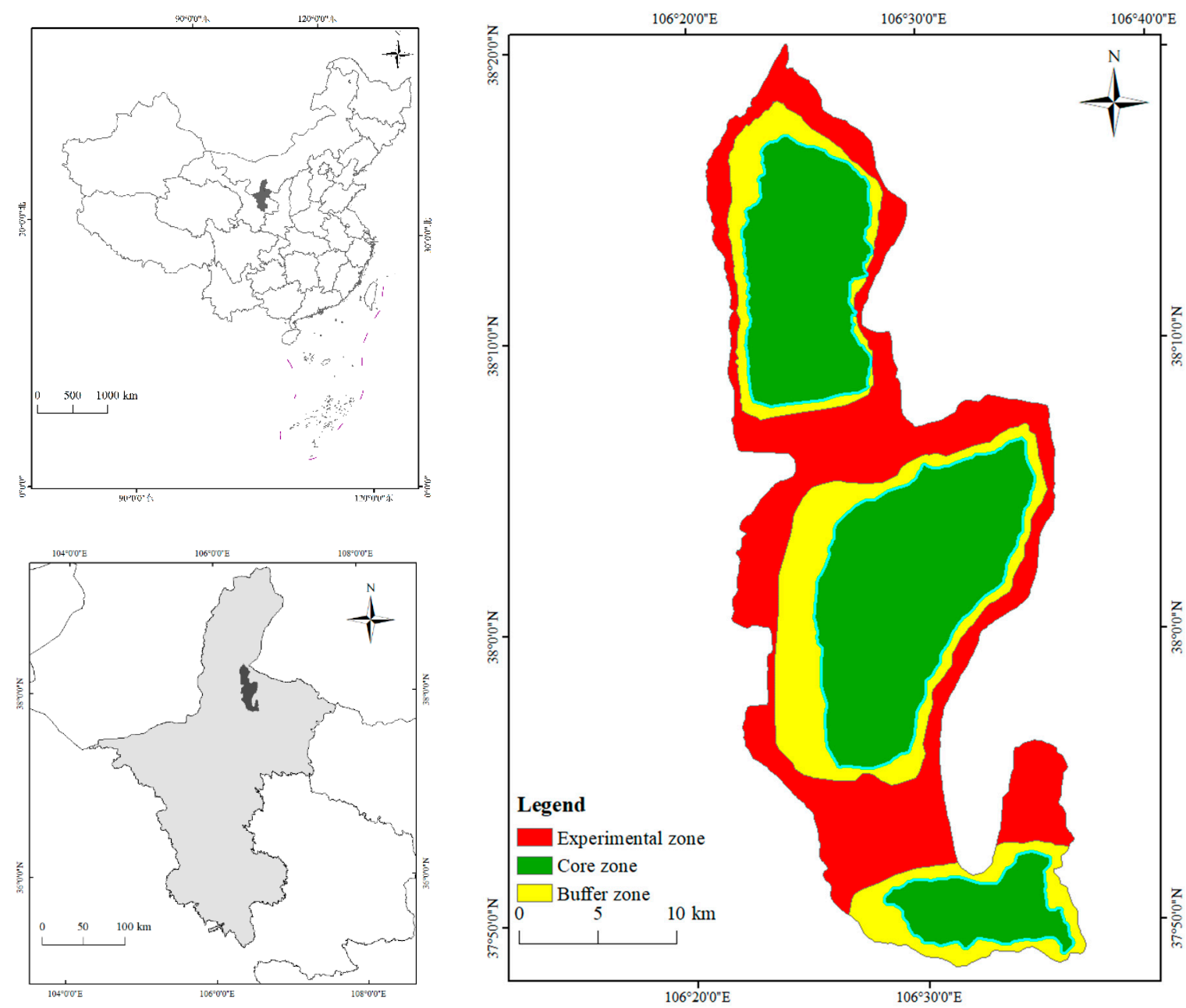

Figure 1. Location of Baijitan Nature Reserve.

The BNR has typical continental climate characteristics. Its climate characteristics are dry conditions with small amounts of concentrated rainfall, extensive evaporation, long winters, short, hot summers, large temperature differences, long periods of sunshine, sufficient light energy, high wintertime and springtime wind and sand, and a short frost-free period. The average annual precipitation is $192.9 \mathrm{~mm}$, with annual maximum and minimum precipitation of 352.4 and $80.4 \mathrm{~mm}$, respectively, and the maximum daily precipitation is $95.4 \mathrm{~mm}$. The maximum snow depth is $130 \mathrm{~mm}$. The annual average temperature is $10.4^{\circ} \mathrm{C}$, and the accumulated temperature is $3351.3^{\circ} \mathrm{C}$. The average minimum temperature of approximately $-6.7^{\circ} \mathrm{C}$ occurs in January and the average maximum temperature of $24.7^{\circ} \mathrm{C}$ occurs in July. The annual extreme maximum and minimum temperatures are $41.4^{\circ} \mathrm{C}$ and $-28^{\circ} \mathrm{C}$, respectively. This region has a maximum annual sunshine duration of $3011 \mathrm{~h}$ and an annual average sunshine duration of $2717 \mathrm{~h}$. The average daily sunshine time is the longest in July at $12.1 \mathrm{~h}$, and the shortest in December at about $9.5 \mathrm{~h}$. 


\subsection{Data Sources}

\subsubsection{Remote Sensing Data Sources}

We obtained normalized difference vegetation index (NDVI) data from the National Aeronautics and Space Administration Moderate-Resolution Imaging Spectroradiometer instrument, which has a temporal resolution of $16 \mathrm{~d}$ and a spatial resolution of $250 \mathrm{~m}$. The dataset eliminated the effects of volcanic eruptions, solar altitude angles, cloud cover, and other factors $[35,36]$. The NDVI is calculated from the near-infrared band $(0.7-1.1 \mu \mathrm{m})$ and the red band $(0.4-0.7 \mu \mathrm{m})$.

$$
N D V I=\frac{R_{N I R}-R_{r e d}}{R_{N I R}+R_{r e d}}
$$

Here, $R_{N I R}$ is the reflectance in the near-infrared spectral region; $R_{\text {red }}$ is the reflectance in the red spectral region.

The data used, known as the MOD13Q1 Vegetation Index, were in Hierarchy Data Format-Earth Observation System (HDF-EOS) format (https://ladsweb.nascom.nasa. gov/, accessed on 15 April 2020). We selected datasets from 2000 to 2019, with 23 volumes per year.

We used digital elevation model (DEM) data with a $30 \mathrm{~m}$ spatial resolution, known as GDEMDEM, from the geospatial data cloud platform of the Computer Network Information Centre of the Chinese Academy of Sciences (http:/ / www.gscloud.cn/, accessed on 15 April 2020).

\subsubsection{Meteorological Data Sources}

We used meteorological data from the Lingwu meteorological station (No. 53614), which is the station nearest to the BNR, lying northwest of the reserve at $38^{\circ} 28^{\prime} \mathrm{N}$ and $106^{\circ} 12^{\prime} \mathrm{E}$. The meteorological data included daily average wind speed, maximum wind speed, and wind direction (16 directions) from 2000 to 2019. We obtained these data from the China Meteorological Science Data Sharing Service Network (http:/ / data.cma.cn, accessed on 25 October 2019). Weather data were from China's National Environmental Monitoring Station (http:/ / www.cnemc.cn, accessed on 26 May 2020) and weather net (http: / / www.tianqi.com, accessed on 26 May 2020). On the basis of different directions and different ranges of sand erosion, we selected 12 cities-Yulin, Yan'an, Xi'an, Changzhi, Zhengzhou, Shiyan, Jining, Wuhan, Zhangjiajie, Hangzhou, Nanchang, and Guilin-for statistics on the March-May air quality characteristics and sand-dust weather frequency from 2017 to 2019. Particles less than 10 microns in diameter $\left(\mathrm{PM}_{10}\right)$ were measured as a daily index value to reflect air quality characteristics.

\subsection{Data Processing}

\subsubsection{Remote Sensing Data Processing}

We used the ArcGIS 10.7 software to convert the NDVI data into TIFF files and then projected, transformed and trimmed the data. We converted the coordinate system to geographic coordinates CGCS2000_3_Degree_GK_CM_105E; the central longitude was $105^{\circ} \mathrm{E}$, and the data were D_China_2000. We resampled the data to a $250 \mathrm{~m}$ resolution to achieve the unification of spatial resolution and clipped the data based on the vector boundary of BNR with the ArcGIS Data Management tools. The maximum value composite method was used to calculate NDVI data from March to May. We obtained slopes for BNR on the basis of the DEM data via the ArcGIS Spatial Analyst tools.

\subsubsection{Wind Speed Processing}

Sand-dust weather mainly occurs in the late spring and early summer. This is because a lack of precipitation makes the surface in arid areas unusually dry and loose, leading to low resistance to wind erosion during this period [37]. Strong winds will blow a large amount of sand into the air, forming sand-dust weather. As a result of the high wind speeds, low precipitation and dry ground conditions, sand-dust weather occurs frequently from March to May in the BNR [21]. 
The condition for sand to move only when the wind speed reaches the sand-driving wind speed was affected primarily by the sand particle size [38]. To process the wind speed data [39], we first linearly interpolated the wind speed. Then, we computed the duration of maximum wind speeds greater than the sand-driving wind speed for winds from the west and northwest from March to May [40]. Lastly, the influence times of sand blown at different wind speed grades were calculated.

\subsubsection{Periodic Division}

In order to research the radiating benefit variation in windbreak and sand fixation in the BNR, the last 20 years can be divided into five phases based on the reserve construction and its overall plan: The first phase of 2000-2003 is the period where it was just promoted as a national nature reserve. The second phase is the period from 2004 to 2007 when the infrastructure was gradually standardized. The third phase is from 2008 to 2011, after the first adjustment of the function zoning. The fourth phase is from 2012 to 2015, after the second adjustment of the function zoning. The fifth phase is from 2016 to 2019, which is the period when the short-term plan of the overall plan was completed and the long-term one was implemented.

\subsubsection{Distribution of Sand}

The terrain of the BNR includes low mountains and hills, gently sloping hills, low mountains and hilly deserts. The wind erosion of soil is serious in the low mountains and hills and gently sloping hills, which are covered with thin soil and gravel [21]. The sand dune chain in the reserve comprises mainly star-type and barchan dunes in the eastern part of the desert, low mountains, and hills. The sand dunes in the western part of the desert low mountains and hills are high, dense, and continuous. We know that the distribution of sand in the reserve is mainly in the low mountain and hilly desert areas. We used remote sensing images with $2 \mathrm{~m}$ spatial resolution captured on 27 July 2016, to exclude the non-sand areas through supervised classification and visual interpretation with the ENVI software. Referring to relevant studies and combined with field investigation, we excluded rocky mountains, water areas, farmlands and other non-sand areas (Figure 2).

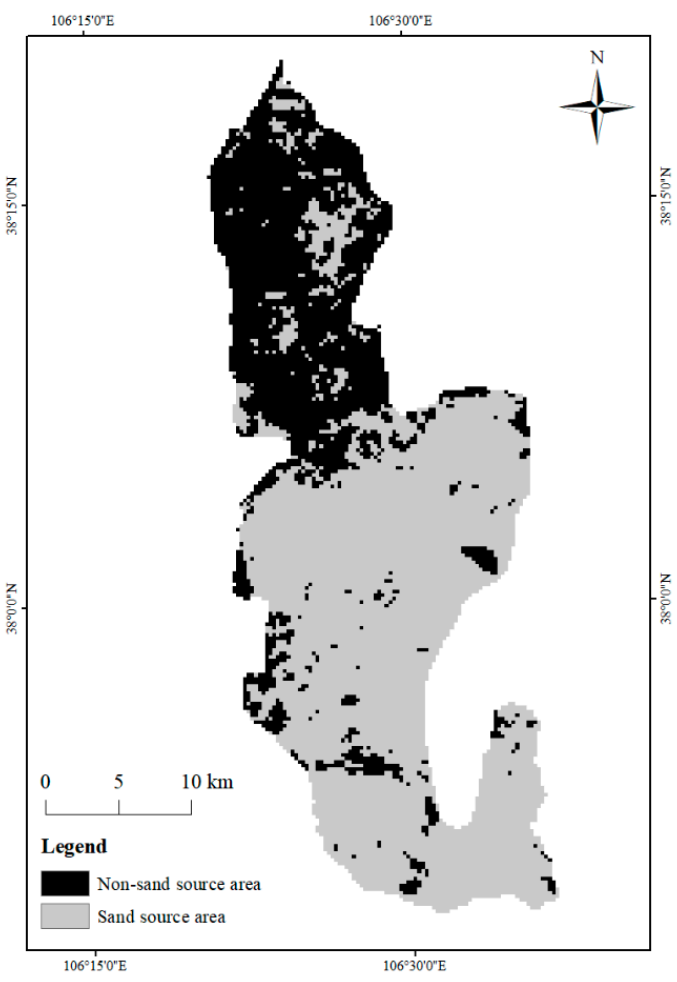

Figure 2. The distribution of sand in Baijitan Nature Reserve. 


\subsubsection{Influence Range Processing}

We calculated the wind erosion distances of various types of particles under different wind speeds using a wind erosion distance model. We classified grain size on the basis of the particle composition of aeolian soil in the nature reserve [21,41], which is dominated by naturally mixed sands (Table 1) [42,43]. Previous studies showed that the sand-driving wind speed of mixed sand is $4.85 \mathrm{~m} \cdot \mathrm{s}^{-1}$ [44]. Then, we determined the wind speed grades on the basis of meteorological classification methods related to average and maximum wind speed (Table 2) [45]. Using ArcGIS, we drew the influence range of sand on a map of China on the basis of the propagation distance of sand particles of various sizes at different wind speeds.

Table 1. Composition of aeolian soil particles in the Baijitan Nature Reserve.

\begin{tabular}{cccc}
\hline & Grain Size & Particle Size (mm) & Proportion (\%) \\
\hline \multirow{2}{*}{ Coarse sand } & $1.00-0.50$ & 0.16 \\
Medium sand & $0.50-0.25$ & 17.98 \\
Fine sand & $0.25-0.10$ & 75.04 \\
& Very fine sand & $0.10-0.05$ & 6.16 \\
\hline \multirow{3}{*}{ Coarse silt } & $0.05-0.01$ & \multirow{2}{*}{0.66} \\
& Medium silt & $0.01-0.005$ & \\
\hline & Fine silt & $0.005-0.002$ & \\
\hline
\end{tabular}

Table 2. The classification of wind speed over sand-driving wind speed in the Baijitan Nature Reserve.

\begin{tabular}{|c|c|c|c|}
\hline Wind Grade & Name & Wind Speed $\left(\mathrm{m} \cdot \mathrm{s}^{-1}\right)$ & Average Wind Speed $\left(\mathrm{m} \cdot \mathrm{s}^{-1}\right)$ \\
\hline 3 & Gentle breeze & $4.85-5.4$ & 5.13 \\
\hline 4 & Moderate breeze & $5.5-7.9$ & 6.70 \\
\hline 5 & Fresh breeze & $8.0-10.7$ & 9.35 \\
\hline 6 & Strong breeze & $10.8-13.8$ & 12.3 \\
\hline 7 & Moderate gale & $13.9-17.1$ & 15.5 \\
\hline 8 & Fresh gale & $17.2-17.4$ & 17.3 \\
\hline
\end{tabular}

\subsection{Calculating Method}

\subsubsection{Method for Calculating Fractional Vegetation Coverage}

There are many methods that use remote sensing data to estimate FVC [44,46-52]. Here, we used a pixel bisection model to estimate FVC on the basis of NDVI data. The calculation formula is as follows:

$$
F V C=\frac{N D V I-N D V I_{\text {soil }}}{N D V I_{\text {evg }}-N D V I_{\text {soil }}}
$$

Here, $N D V I_{\text {veg }}$ is the pixel value of pure vegetation, which is close to 1 in theory but is affected by the vegetation type, soil conditions and other factors; $N D V I_{\text {soil }}$ is the pixel value of pure soil, which is close to 0 in theory but is affected by atmosphere, surface humidity, surface roughness, soil type, and soil color. Different studies have used various methods for choosing $N D V I_{\text {veg }}$ and $N D V I_{\text {soil }}$. In the absence of detailed regional vegetation and soil spectral data for the Yinchuan City vegetation coverage inversion in the present study, we referred to the approximate estimation algorithm to calculate the $N D V I_{\text {soil }}$ and $N D V I_{\text {veg }}$ values of 0.05 and 0.70 , respectively [53-59].

According to [60], FVC can be divided into four types: poor coverage $(<10 \%)$, low coverage (10-30\%), medium coverage (30-50\%), and high coverage $(>50 \%)$. 


\subsubsection{Method for Calculating Influence Range}

The sand particle erosion distance varies under different wind speeds. On the basis of the average wind speed of different wind speed grades and the relationship between wind speed and the turbulent exchange coefficient, we calculated the erosion distance and times of different grain sizes under different wind speeds using von Karman's empirical distance transmission formula:

$$
\begin{aligned}
L & =\frac{40 \varepsilon \mu^{2} V}{\rho_{s}^{2} g^{2} d^{4}} \\
t & =\frac{40 \varepsilon \mu^{2}}{\rho_{s}^{2} g^{2} d^{4}}
\end{aligned}
$$

Here, $L$ is the sand erosion distance $(\mathrm{km}) ; \mathrm{t}$ is the duration of sand particles in the air (s); $\varepsilon$ is the turbulent exchange coefficient $\left(\mathrm{cm}^{2} \cdot \mathrm{s}^{-1}\right)$, which changes with wind speed [32-34,61]; $\mu$ is the viscosity coefficient of air $\left(1.98 \times 10^{-5} \mathrm{~Pa} \cdot \mathrm{s}\right) ; V$ is the wind speed $\left(\mathrm{m} \cdot \mathrm{s}^{-1}\right) ; \rho_{s}$ is the sand particle density $\left(1.4 \mathrm{~g} \cdot \mathrm{cm}^{-3}\right) ; g$ is the acceleration due to of gravity $\left(10 \mathrm{~m} \cdot \mathrm{s}^{-2}\right)$; and $d$ is the sand grain size $(\mathrm{mm})$.

\subsubsection{Method for Calculating Wind Erosion}

Dong Zhibao established a wind erosion loss model on the basis of the wind tunnel experiments and field observations of Liudaogou, a small watershed in Shaanxi Province at the northeast edge of Mu Us Sandy Land with a Loess Hill landform type covered by sheet sand [31]. This area is close to the BNR both in terms of its geographical location and natural conditions. This wind erosion loss model has been used in many studies and has achieved good results [32-34]. Therefore, we estimated wind erosion in the BNR on the basis of this model. We divided remote sensing data of the BNR into 11,811 $250 \mathrm{~m} \times 250 \mathrm{~m}$ grids. There was an error of $10 \mathrm{~km}^{2}$ between the reserve's total area in the model and the actual situation because of the grid accuracy and clipping. By calculating the wind erosion amount per grid of sand source in the reserve, we could obtain the total wind erosion amount by adding the grids one by one. The specific wind erosion model of the sand area can be expressed as follows [31-34]:

$Q=\int_{t} \int_{x} \int_{y}\left\{3.90\left(1.0413+0.04413 \theta+0.0021 \theta^{2}-0.0001 \theta^{3}\right) \times\left[\frac{V^{2}\left(8.2 \times 10^{-5}\right)^{V_{c r}} S_{D R}^{2}}{\left(H^{8} d^{2} F\right) x, y, t}\right]\right\} d_{x} d_{y} d_{t}$

Here, $Q$ is wind erosion ( $\mathrm{t})\left(1 \mathrm{t}=10^{3} \mathrm{~kg}\right) ; \theta$ is slope $\left(^{\circ}\right) ; V$ is wind speed $\left(\mathrm{m} \cdot \mathrm{s}^{-1}\right) ; V_{C R}$ is vegetation coverage (\%); $S_{D R}$ is the damage rate of an artificial surface structure (\%), which was not considered in the present study, and thus, a value of $100 \%$ was taken; $H$ is the relative humidity, which was calculated using the average relative humidity values from when the wind speeds exceeded the sand-driving wind speed ( $35 \%$ was the value used in the present study); $D$ is the sand particle size $(\mathrm{mm})$, with the average particle size of $0.025 \mathrm{~mm}$ taken; $F$ is the soil hardness $\left(\mathrm{n} \cdot \mathrm{cm}^{-2}\right)$, which refers to the parameter table of the soil texture model $\left(0.9 \mathrm{n} \cdot \mathrm{cm}^{-2}\right.$ was taken); $x$ and $y$ are $0.25 \mathrm{~km}$ based on the grid size; and $T$ is the duration (s), which is the total annual time where the wind speeds exceeded the sand-driving wind speed.

\subsubsection{Method for Calculating Dust Deposition}

The dust deposition amount is an important index for measuring wind erosion. The degree of influence of different administrative regions was evaluated by calculating the downwind dust deposition. We evaluated the benefits of windbreaks and sand fixation in the BNR by calculating the dust deposition reduction in downwind areas.

We used the following equation for calculating dust deposition in downwind areas:

$$
S_{p}=A_{p} \times \sum_{i=n}^{m} \frac{Q_{i}}{A_{i}}
$$


Here, $S_{p}$ is the dust deposition ( $\mathrm{t}$ ) with the influence range $p$ of sand (Table 3); $A_{p}$ is the area of the region with a given sand particle influence range level $p\left(\mathrm{~km}^{2}\right) ; m$ and $n$ are the highest and lowest wind speed grades, respectively; $Q_{i}$ is the erosion amount of the nature reserve $(\mathrm{t})$ when the wind speed is $I ; A_{i}$ is the falling range of sand $\left(\mathrm{km}^{2}\right)$ when the wind speed is $i$; and $i$ is the wind speed grade.

Table 3. The classification of wind speed over sand-driving wind speed in the Baijitan Nature Reserve.

\begin{tabular}{cccc}
\hline Level & $\begin{array}{c}\text { Influence } \\
\text { Range } \mathbf{( k m )}\end{array}$ & $\begin{array}{c}\text { China's Land Area within } \\
\text { the Radiating Range } \mathbf{( k m}^{\mathbf{2}} \mathbf{)}\end{array}$ & $\begin{array}{c}\text { The Grade of Wind Speed, } \\
\text { Affected by the Radiating Range }\end{array}$ \\
\hline 1 & $0.75-0.81$ & $7.80 \times 10^{-1}$ & 3 \\
2 & $0.81-1.25$ & $5.71 \times 10^{1}$ & 3,4 \\
3 & $1.25-1.9$ & $8.21 \times 10^{1}$ & $3,4,5$ \\
4 & $1.9-2.95$ & $1.20 \times 10^{2}$ & $3,4,5,6$ \\
5 & $2.95-4.59$ & $1.69 \times 10^{2}$ & $3,4,5,6,7$ \\
6 & $4.59-508.05$ & $2.43 \times 10^{5}$ & $3,4,5,6,7,8$ \\
7 & $508.05-777.97$ & $2.94 \times 10^{5}$ & $4,5,6,7,8$ \\
8 & $777.97-1184.99$ & $6.21 \times 10^{5}$ & $5,6,7,8$ \\
9 & $1184.99-1840.74$ & $9.39 \times 10^{5}$ & $6,7,8$ \\
10 & $1840.74-2871.86$ & $2.53 \times 10^{4}$ & 7,8 \\
\hline
\end{tabular}

We used the following equation for calculating the dust deposition in different administrative regions:

$$
S_{D}=\sum_{p}\left(S_{p} \times \frac{S_{D_{p}}}{A_{p}}\right)
$$

Here, $S_{D}$ is the dust deposition in different administrative regions, with $D$ representing the administrative region, and $S_{D p}$ is the area of different administrative regions in the area with the dust influence range $p$.

We used the following equation for calculating the dust deposition reduction in the reserve from 2000 to 2019.

$$
S_{r}=\sum_{y=y_{s}}^{y_{e}} S_{y}-\left(y_{e}-y_{s}+1\right) \times S_{y_{s}}
$$

Here, $S_{r}$ is the dust deposition reduction $(\mathrm{t}) ; y_{s}$ and $y_{e}$ are the starting and ending years, respectively, of the period in which the dust deposition reduction time series was calculated; $y$ is the year in which the dust deposition occurred; $S_{y}$ is the dust deposition in year $y(t)$; and $s_{y_{s}}$ is dust deposition in year $y_{s}(t)$.

\subsubsection{Verification Method for Dust Deposition}

We counted the days where sand or floating dust occurred in different cities and the days when the $\mathrm{PM}_{10}$ index did not reach the second level of air quality. We then used nonparametric analysis (Spearman's rank correlation coefficient) to study the $\mathrm{PM}_{10}$ concentration response to different wind speeds $[62,63]$. We used the SPSS 22.0 software to analyze the correlation between $\mathrm{PM}_{10}$ and sand wind duration series (the current day, the next day, the third day, and the fourth day).

\section{Results}

\subsection{Analysis of Wind Speed}

An analysis of the wind speeds in the reserve over the past 20 years (Figure 3) showed that high wind speeds from the WNW and NW occurred at frequencies of $10 \%$ and $9.72 \%$, respectively, and the average wind speeds from the WNW and NW were 8.12 and $7.94 \mathrm{~m} \cdot \mathrm{s}^{-1}$, respectively. For winds from the $\mathrm{W}$, the frequency was low, but the wind speed was high at an average of $6.55 \mathrm{~m} \cdot \mathrm{s}^{-1}$, which is second only to the WNW and NW winds. 


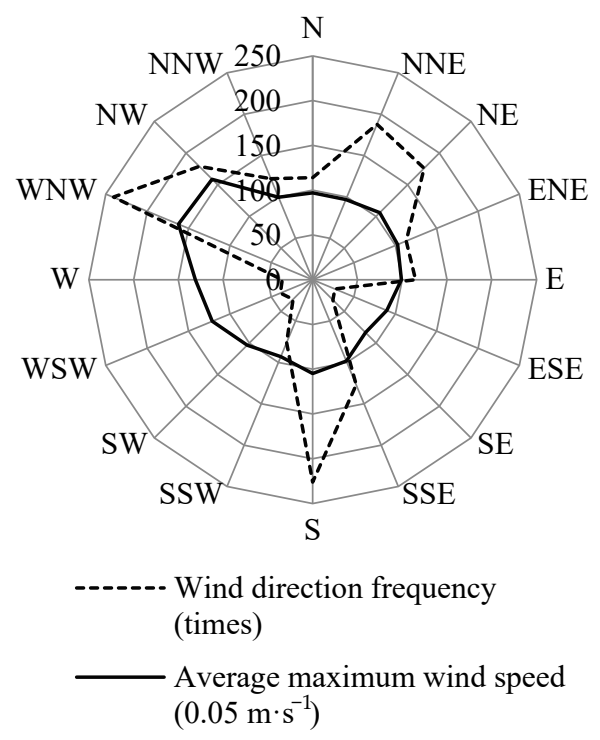

Figure 3. Wind speeds and direction in Baijitan Nature Reserve.

Based on time variations in the wind-blown sand (Figure 4), strong breezes and moderate and fresh gales (grades 6, 7, and 8) mainly occurred in the first and second phases and moderate and fresh gales (grades 7 and 8) disappeared in the third phase. In addition, the duration of fresh breezes (grade 5) was significantly reduced from $702.05 \mathrm{~h}$ in the first phase to $37.36 \mathrm{~h}$ in the fifth phase. In addition to this, the change in moderate breezes (grade 4) was obvious as well because the duration of moderate breezes was getting smaller and smaller. It was, however, the dominant type of winds in the BNR, since its duration-nearly $400 \mathrm{~h}$-in the fifth phase was the longest. The one that changed the least was gentle breeze (grade 3), which has the lowest potential to cause sand disasters compared with other types of winds. The duration of gentle breezes, over $200 \mathrm{~h}$, was the second longest in the fifth phase.

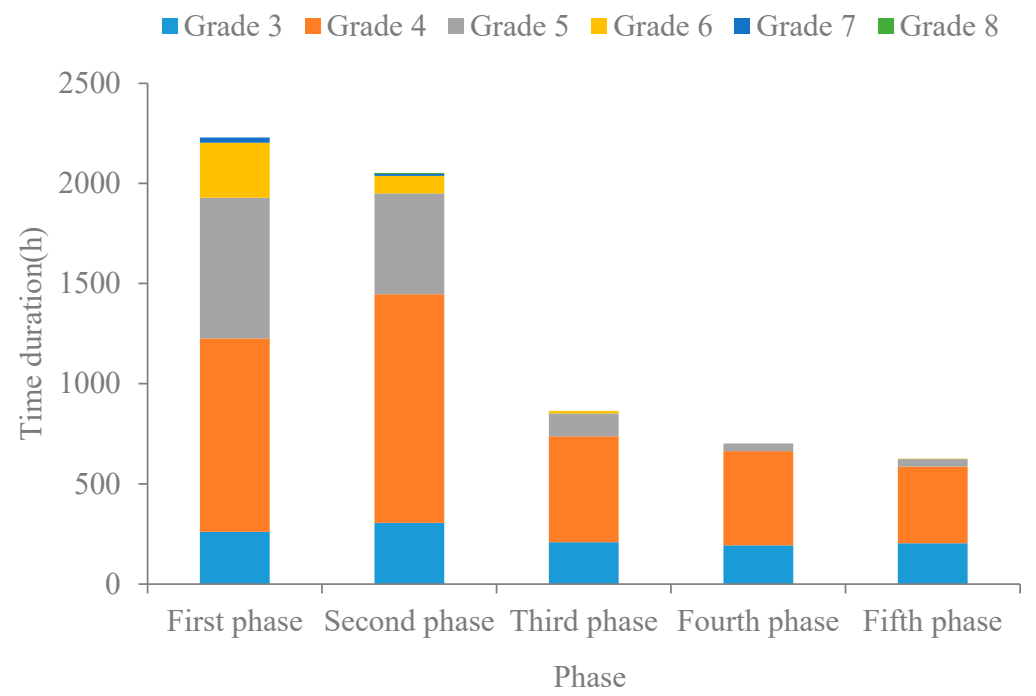

Figure 4. Temporal variations of wind-blown sand.

\subsection{Analysis of Fractional Vegetation Coverage}

According to the spatial distribution law of FVC in different phases (Figure 5), the FVC of BNR exhibited an increasing trend. The characteristics of vegetation cover types in different phases were obvious. In the first phase, low coverage had the absolute advantage, with an area of $555.25 \mathrm{~km}^{2}$, accounting for $75.22 \%$ of the total area of the reserve. Poor 
coverage, accounting for $21.11 \%$, came second only to low coverage, with an area of $155.88 \mathrm{~km}^{2}$. The distribution of medium and high coverage was very small, together accounting for only $3.67 \%$ of the total area of the reserve. In the second phase, poor coverage decreased, and low coverage still accounted for the highest total area (81.95\%). The area of the medium and high coverage types increased, increasing by $3.39 \%$ and $0.08 \%$, respectively. Low coverage and medium coverage in the third phase became the main types, with a proportion of $94.90 \%$. Poor coverage, accounting for only $0.32 \%$ in the fourth phase, became the least prevalent type and medium coverage, accounting for $54.96 \%$, grew at a rapid rate, becoming one of the most prevalent vegetation types. In the fifth phase, low coverage gradually changed to medium coverage, and the area difference between them increased, with the proportion of medium coverage reaching $66.13 \%$. High coverage increased significantly, with an area of $100.81 \mathrm{~km}^{2}$.

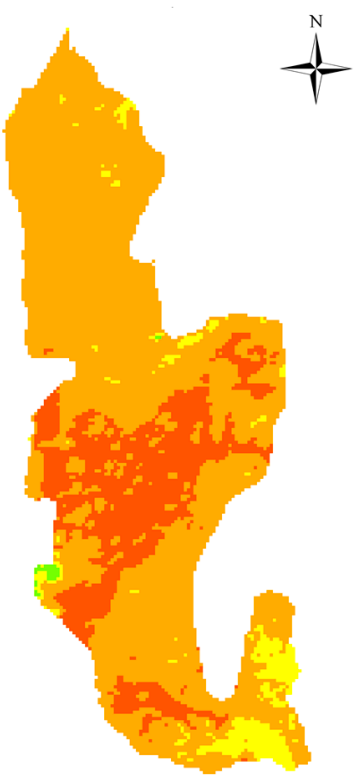

(a)

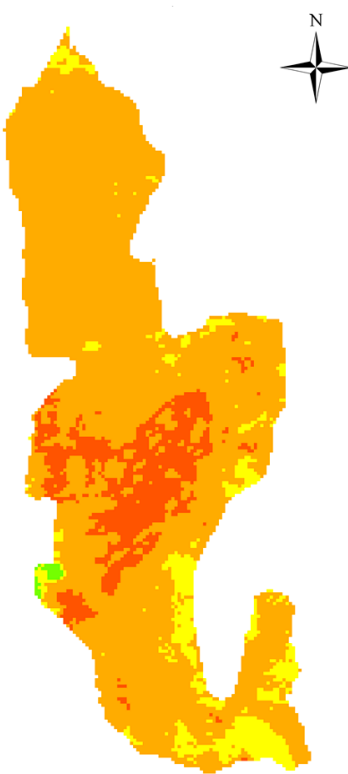

(b)

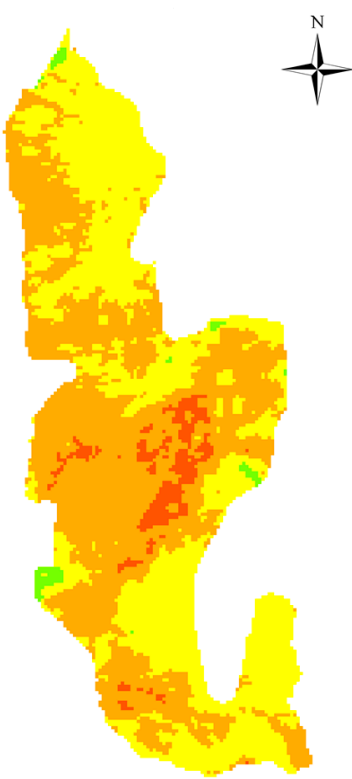

(c)
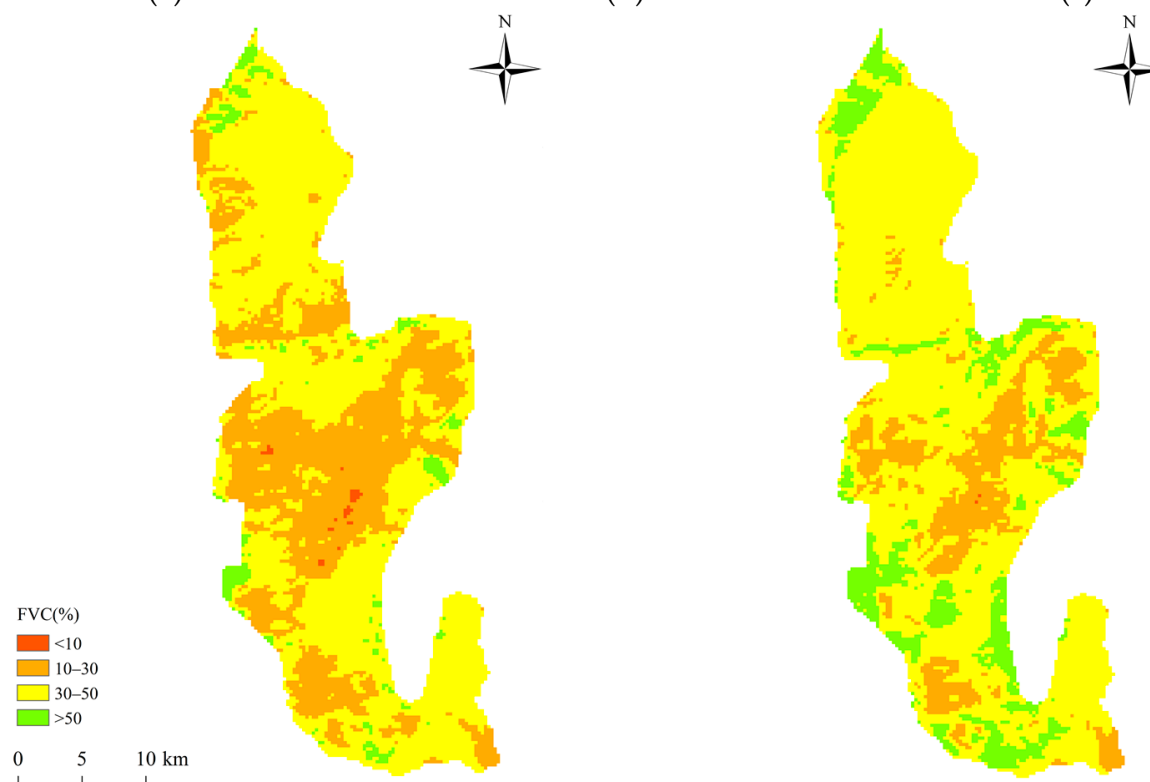

(d)

Figure 5. The spatial distribution law of fractional vegetation coverage (FVC) in different phases. (a) First phase; (b) second phase; (c) third phase; (d) forth phase; (e) fifth phase. 


\subsection{Attenuation by Windbreak and Sand Fixation}

Based on the sand erosion distance and influence time (Table 4), the influence range varied under different wind speeds, showing the following characteristics:

Table 4. Sand erosion distance and influence time.

\begin{tabular}{|c|c|c|c|c|}
\hline Name & Particle Size (mm) & Wind Speed $\left(\mathrm{m} \cdot \mathrm{s}^{-1}\right)$ & Erosion Distance (km) & Influence Time (s) \\
\hline \multirow{6}{*}{$\begin{array}{l}\text { Medium silt, fine silt } \\
\text { and clay }\end{array}$} & \multirow{6}{*}{$<0.01$} & $4.85-5.4$ & $>508.05$ & $>94,082.98$ \\
\hline & & $5.5-7.9$ & $>777.97$ & $>94,082.98$ \\
\hline & & $8.0-10.7$ & $>1184.99$ & $>98,477.32$ \\
\hline & & $10.8-13.8$ & $>1840.74$ & $>110,746.84$ \\
\hline & & $13.9-17.1$ & $>2871.86$ & $>133,387.03$ \\
\hline & & $17.2-17.4$ & $>2947.68$ & $>167,945.18$ \\
\hline \multirow{6}{*}{ Coarse silt } & \multirow{6}{*}{$0.01-0.05$} & $4.85-5.4$ & $0.75-508.05$ & $150.53-94,082.98$ \\
\hline & & $5.5-7.9$ & $0.81-777.97$ & $157.56-96,428.95$ \\
\hline & & $8.0-10.7$ & $1.25-1184.99$ & 177.19-98,477.32 \\
\hline & & $10.8-13.8$ & $1.90-1840.74$ & $213.42-110,746.84$ \\
\hline & & $13.9-17.1$ & $2.95-2871.86$ & $268.71-133,387.03$ \\
\hline & & $17.2-17.4$ & $4.59-2947.68$ & $272.62-167,945.18$ \\
\hline \multirow{6}{*}{ Very fine sand } & \multirow{6}{*}{$0.05-0.1$} & $4.85-5.4$ & $0.05-0.81$ & $9.41-154.29$ \\
\hline & & $5.5-7.9$ & $0.05-1.24$ & $9.85-150.53$ \\
\hline & & $8.0-10.7$ & $0.08-1.90$ & $11.07-157.56$ \\
\hline & & $10.8-13.8$ & $0.12-2.95$ & $13.34-177.19$ \\
\hline & & $13.9-17.1$ & $0.18-4.59$ & $16.79-213.42$ \\
\hline & & $17.2-17.4$ & $0.29-4.72$ & $17.04-268.71$ \\
\hline \multirow{6}{*}{ Fine sand } & \multirow{6}{*}{$0.10-0.25$} & $4.85-5.4$ & $1.20 \times 10^{-2}-0.05$ & $0.24-9.64$ \\
\hline & & $5.5-7.9$ & $1.30 \times 10^{-2}-0.08$ & $0.25-9.41$ \\
\hline & & $8.0-10.7$ & $1.99 \times 10^{-2}-0.12$ & $0.28-9.85$ \\
\hline & & $10.8-13.8$ & $3.03 \times 10^{-2}-0.18$ & $0.34-11.07$ \\
\hline & & $13.9-17.1$ & $4.71 \times 10^{-2}-0.29$ & $0.43-13.34$ \\
\hline & & $17.2-17.4$ & $7.35 \times 10^{-2}-0.29$ & $0.44-16.79$ \\
\hline \multirow{6}{*}{ Medium sand } & \multirow{6}{*}{$0.25-0.50$} & $4.85-5.4$ & $7.48 \times 10^{-5}-1.30 \times 10^{-2}$ & $0.02-0.25$ \\
\hline & & $5.5-7.9$ & $8.13 \times 10^{-4}-1.99 \times 10^{-2}$ & $0.02-0.24$ \\
\hline & & $8.0-10.7$ & $1.24 \times 10^{-3}-3.03 \times 10^{-2}$ & $0.02-0.25$ \\
\hline & & $10.8-13.8$ & $1.90 \times 10^{-3}-4.71 \times 10^{-2}$ & $0.02-0.28$ \\
\hline & & $13.9-17.1$ & $2.95 \times 10^{-3}-7.35 \times 10^{-2}$ & $0.03-0.34$ \\
\hline & & $17.2-17.4$ & $4.59 \times 10^{-3}-7.55 \times 10^{-2}$ & $0.03-0.43$ \\
\hline \multirow{6}{*}{ Coarse sand } & \multirow{6}{*}{$0.5-1.0$} & $4.85-5.4$ & $4.68 \times 10^{-6}-8.13 \times 10^{-4}$ & $9.41 \times 10^{-3}-0.02$ \\
\hline & & $5.5-7.9$ & $5.08 \times 10^{-6}-1.24 \times 10^{-3}$ & $9.85 \times 10^{-3}-0.02$ \\
\hline & & $8.0-10.7$ & $7.78 \times 10^{-6}-1.90 \times 10^{-3}$ & $1.12 \times 10^{-2}-0.02$ \\
\hline & & $10.8-13.8$ & $1.18 \times 10^{-5}-2.95 \times 10^{-3}$ & $1.33 \times 10^{-2}-0.02$ \\
\hline & & $13.9-17.1$ & $1.84 \times 10^{-5}-4.59 \times 10^{-3}$ & $1.68 \times 10^{-2}-0.02$ \\
\hline & & $17.2-17.4$ & $2.87 \times 10^{-5}-4.72 \times 10^{-3}$ & $1.70 \times 10^{-2}-0.03$ \\
\hline
\end{tabular}

Coarse sand, medium sand, fine sand and very fine sand only affected the reserve and surrounding communities. When the maximum wind speed was $17.4 \mathrm{~m} \cdot \mathrm{s}^{-1}$, the maximum influence distances of coarse sand, medium sand, fine sand and very fine sand were 4.72 , $75.5,290$, and $4720 \mathrm{~m}$, respectively, and the longest influence times were $0.03,0.43,16.79$, and $268.71 \mathrm{~s}$, respectively. The predominant movement modes were creeping and saltation. 
Coarse silt can affect the downwind area under a moderate gale (grade 7) (Figure 6). Coarse silt can easily become a suspended load. Once the sand-driving wind speed of mixed sand is reached, coarse silt will move to high altitudes. Based on the influence range of coarse silt, when a gentle breeze (grade 3 ) occurred, the influence distance reached $508.05 \mathrm{~km}$ and the longest influence time was $26 \mathrm{~h}$, and six administrative regions-Shanxi Province, Inner Mongolia Autonomous Region, Henan Province, Shaanxi Province, Gansu Province, and Ningxia Hui Autonomous Region-were affected. When a moderate breeze (grade 4) occurred, the influence distance reached $777.97 \mathrm{~km}$ and 10 administrative regions were affected. When a fresh breeze (grade 5) occurred, the influence distance reached $1184.99 \mathrm{~km}$. The nearest distance between the reserve and the coastline was $957.67 \mathrm{~km}$, and thus part of the influence range was beyond the coastline. In this case, 18 administrative regions were affected. When a strong breeze (grade 6) occurred, the maximum influence distance reached $1840.74 \mathrm{~km}$, meaning that part of the influence range was beyond the coastline, and the longest influence time was $30 \mathrm{~h}$. In this case, 26 administrative regionsBeijing Municipal, Tianjin Municipal, Hebei Province, Shanxi Province, Inner Mongolia Autonomous Region, Liaoning Province, Jilin Province, Shanghai Province, Jiangsu Province, Zhejiang Province, Anhui Province, Fujian Province, Jiangxi Province, Shandong Province, Henan Province, Hubei Province, Hunan Province, Guangdong Province, Guangxi Zhuang Autonomous Region, Hainan Province, Chongqing Municipal, Sichuan Province, Guizhou Province, Shaanxi Province, Gansu Province, and Ningxia Hui Autonomous Region-were affected.

When moderate and fresh gales (grades 7 and 8) occurred, the maximum influence distance exceeded the coastline (the longest distance between the reserve and the coastline is $1903.12 \mathrm{~km}$ ), and the affected administrative area was the same as that affected by a strong breeze (grade 6). The longest impact times were 37 and $46 \mathrm{~h}$.

When the sand-driving wind speed was reached, the air quality of the downwind region could be affected by medium, fine, and clay silt (Figure 7), which easily become suspended loads such as coarse silt. When the radiating distance reached $508.05 \mathrm{~km}$, they began to descend gradually. When the wind speeds reached grades 7 and 8 , the shortest radiating distance could reach $2871.86 \mathrm{~km}$, which is enough to go beyond China's coastline. Due to the influence of forests, mountain ranges, cities, and other factors, even if it does not reach the theoretical landing range, the medium silt, fine silt and clay will fall to different degrees.

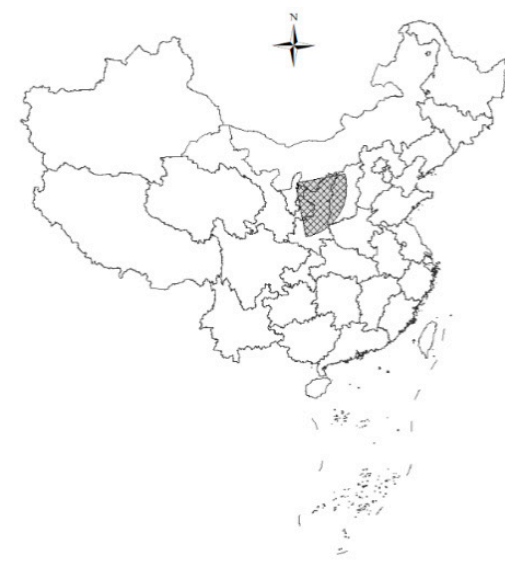

(a)
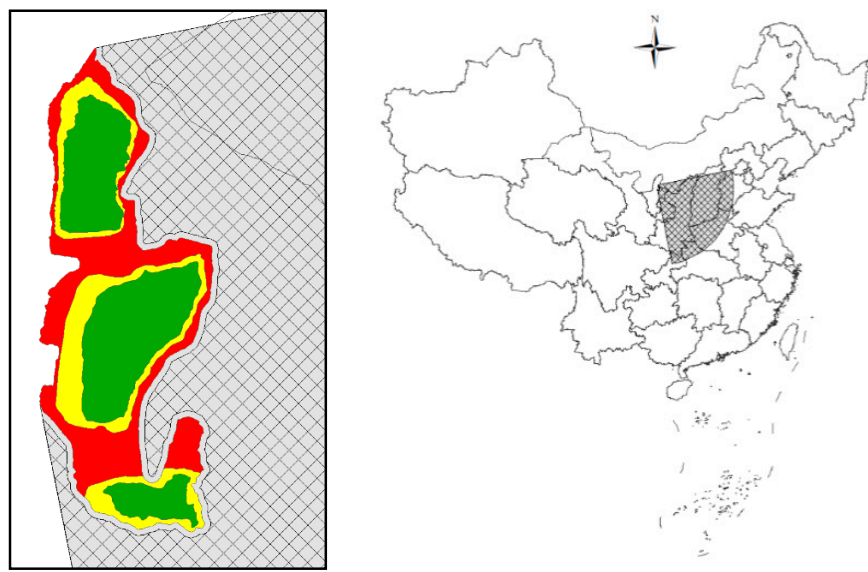

(b)

Figure 6. Cont. 


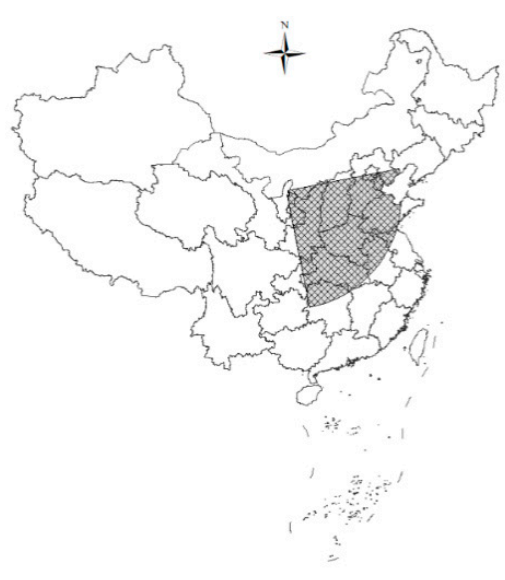

(c)

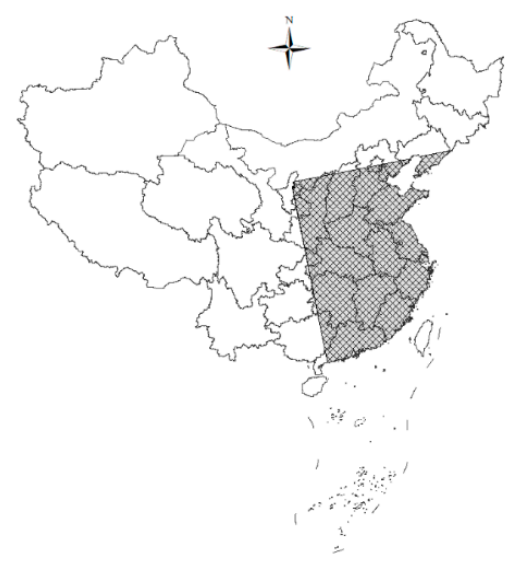

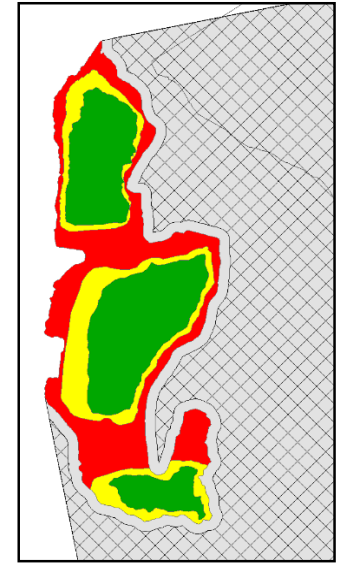

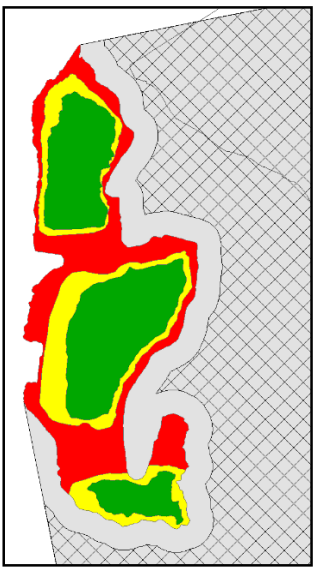

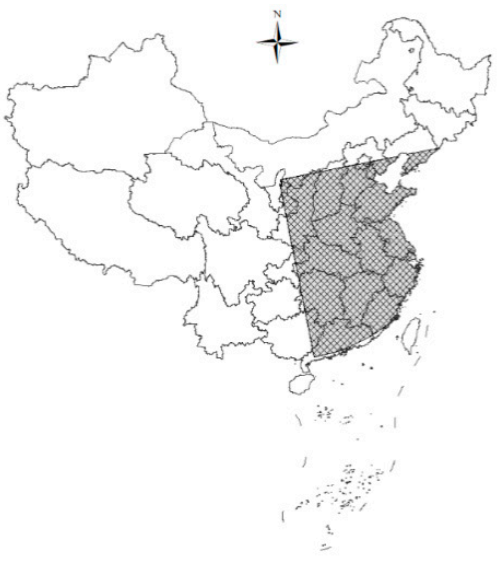

(d)
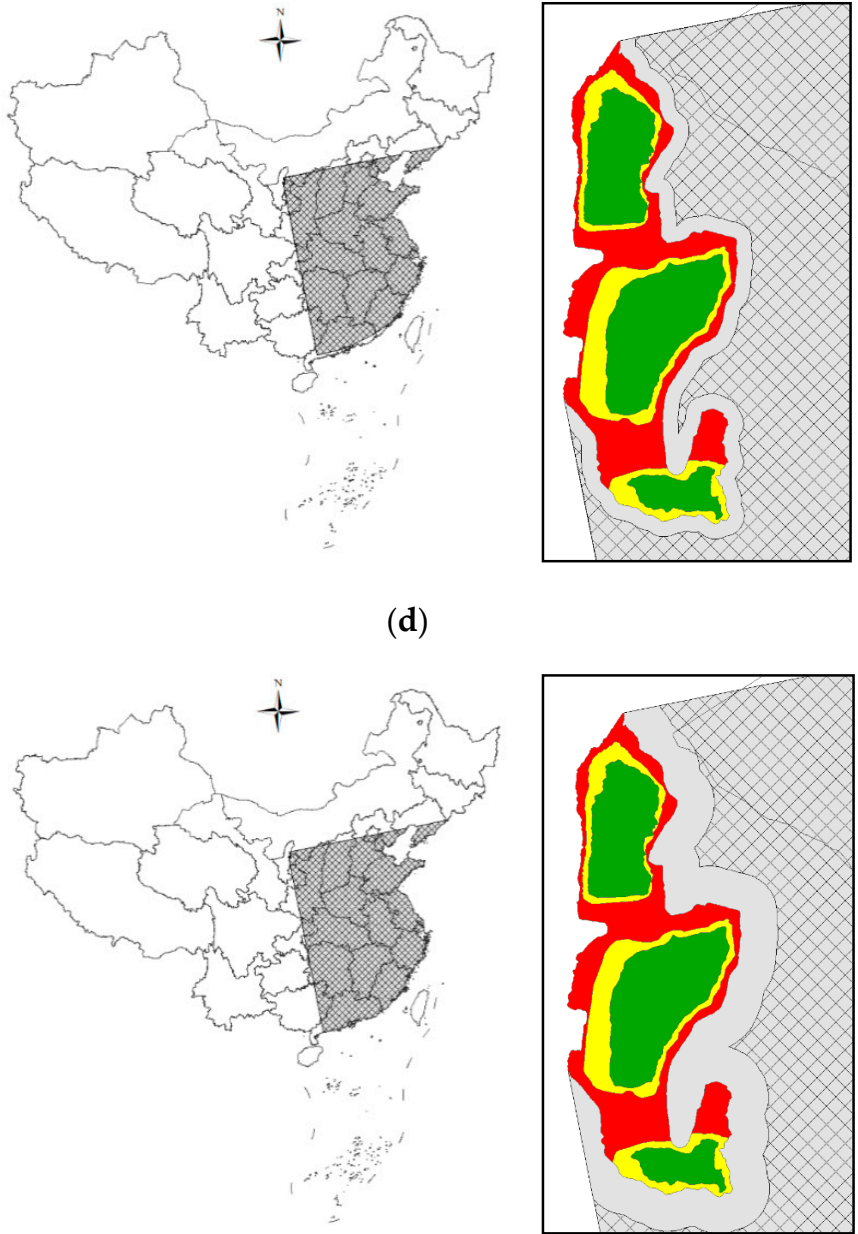

\section{Legend}

Falling range

Influence range

(e)

Figure 6. Influence range of coarse silt in the Baijitan Nature Reserve. (a) with gentle breeze (grade 3); (b) with moderate breeze (grade 4); (c) with fresh breeze (grade 5); (d) with strong breeze (grade 6); (e) with moderate gale (grade 7); (f) with fresh gale (grade 8).

\subsection{Evaluating the Benefits of Windbreak and Sand Fixation}

Based on the spatial distribution map of dust deposition over the past 20 years (Figure 8), the dust deposition in downwind areas decreased with increased distance.

Based on the attenuation law, the influence range could be divided into four regions. In each of these regions, the deposition over the past 20 years tended to gradually decrease. 


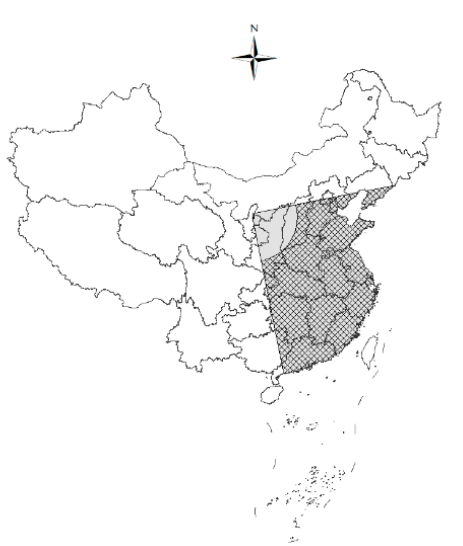

(a)

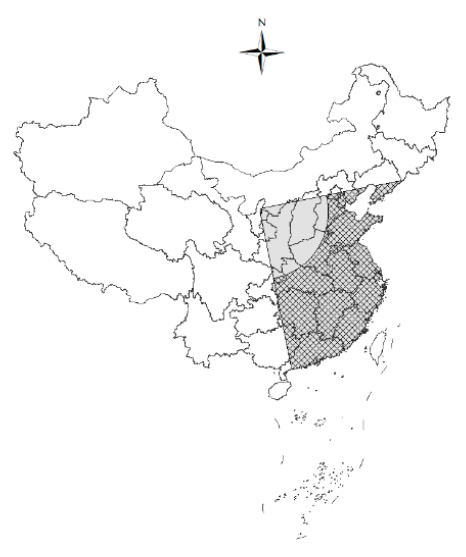

(b)

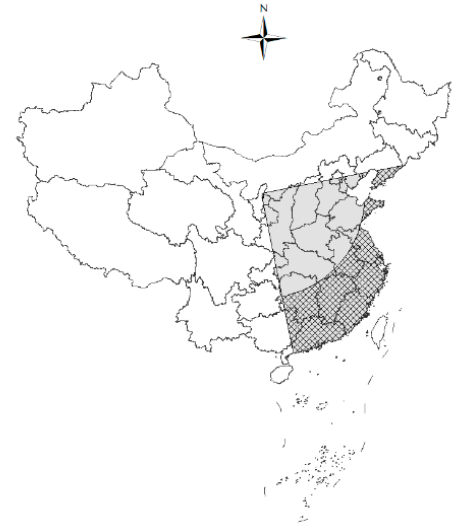

(c)

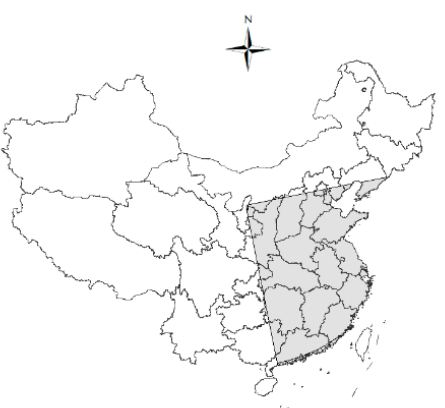

Legend

Falling range Influence range

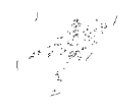

(d)

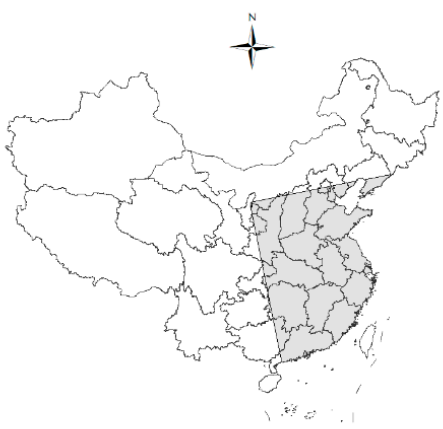

(e)

Figure 7. Influence range of medium silt, fine silt and clay in Baijitan Nature Reserve. (a) In gentle breeze (grade 3); (b) with moderate breeze (grade 4); (c) with fresh breeze (grade 5); (d) with strong breeze (grade 6); (e) with moderate gale (grade 7).

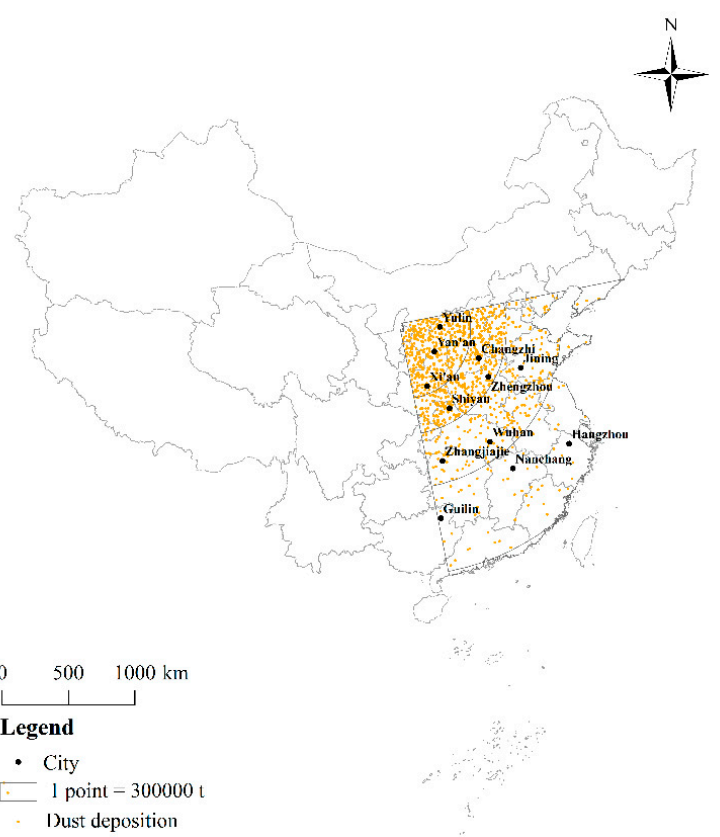

Figure 8. Spatial distribution map of dust deposition from 2000 to 2019. 
The influence area with an influence range level less than or equal to six was $2.43 \times 10^{5} \mathrm{~km}^{2}$ and the dust deposition, accounting for $36.21 \%$ of the total dust deposition over the past 20 years, was $8.16 \times 10^{7} \mathrm{t}$. The periodical depositions were $3.01 \times 10^{7}$, $2.78 \times 10^{7}, 1.05 \times 10^{7}, 7.47 \times 10^{6}$, and $5.66 \times 10^{6} \mathrm{t}$, respectively.

The influence area with an influence range level of seven was $2.94 \times 10^{5} \mathrm{~km}^{2}$ and the dust deposition, accounting for $34.19 \%$ of the total dust deposition, was $7.70 \times 10^{7} \mathrm{t}$. The periodical depositions were $3.07 \times 10^{7}, 2.72 \times 10^{7}, 8.94 \times 10^{6}, 6.05 \times 10^{6}$, and $4.20 \times 10^{6} \mathrm{t}$, respectively.

The influence area with an influence range level of eight was $6.21 \times 10^{5} \mathrm{~km}^{2}$ and the dust deposition, accounting for $23.38 \%$ of the total dust deposition, was $5.27 \times 10^{7} \mathrm{t}$. The periodical depositions were $2.99 \times 10^{7}, 1.79 \times 10^{7}, 3.27 \times 10^{6}, 8.84 \times 10^{5}$, and $7.48 \times 10^{5} \mathrm{t}$, respectively.

The influence area with an influence range level of greater than or equal to nine was the largest $\left(9.64 \times 10^{5} \mathrm{~km}^{2}\right)$, but the dust deposition, accounting for only $6.22 \%$ of the total dust deposition, was the smallest $\left(1.40 \times 10^{7} \mathrm{t}\right)$. The periodical depositions were $1.04 \times 10^{7}$, $3.24 \times 10^{6}, 3.39 \times 10^{5}, 0$, and $5.25 \times 10^{4}$, respectively.

\subsection{Attenuation by Windbreak and Sand Fixation}

Based on the dust deposition of administrative regions in China (Figure 9), the dust deposition reduction in the administrative regions is closely related to the influence range, level of distribution, and influence area. A shorter influence distance and larger influence area yielded a greater reduction in dust deposition and a greater benefit from windbreak and sand fixation. In addition, the deposition in the administrative areas decreased gradually. Shaanxi Province, which experienced the greatest benefit from windbreak and sand fixation, is distributed in the influence range level of 6-7, with an influence area of $1.65 \times 10^{5} \mathrm{~km}^{2}$. Its dust depositions in five phases were $2.04 \times 10^{7}, 1.83 \times 10^{7}, 6.63 \times 10^{6}$, $4.65 \times 10^{6}$, and $3.48 \times 10^{6} \mathrm{t}$. The areas that benefited the second most were Hubei and Henan Provinces. The influence area of Hubei Province is the largest of all the administrative regions in the downwind direction, reaching $1.83 \times 10^{7} \mathrm{~km}^{2}$. The dust deposition reductions in Hubei and Henan Provinces were $5.31 \times 10^{7}$ and $5.59 \times 10^{7} \mathrm{t}$, respectively, exceeding the dust deposition over the past 20 years. Similarly, the periodical deposition in the two provinces showed a downwards trend. For instance, the deposition in different phases of Hubei Province were $1.11 \times 10^{7}, 7.26 \times 10^{6}, 1.68 \times 10^{6}, 8.01 \times 10^{5}$, and $5.93 \times 10^{5} \mathrm{t}$.

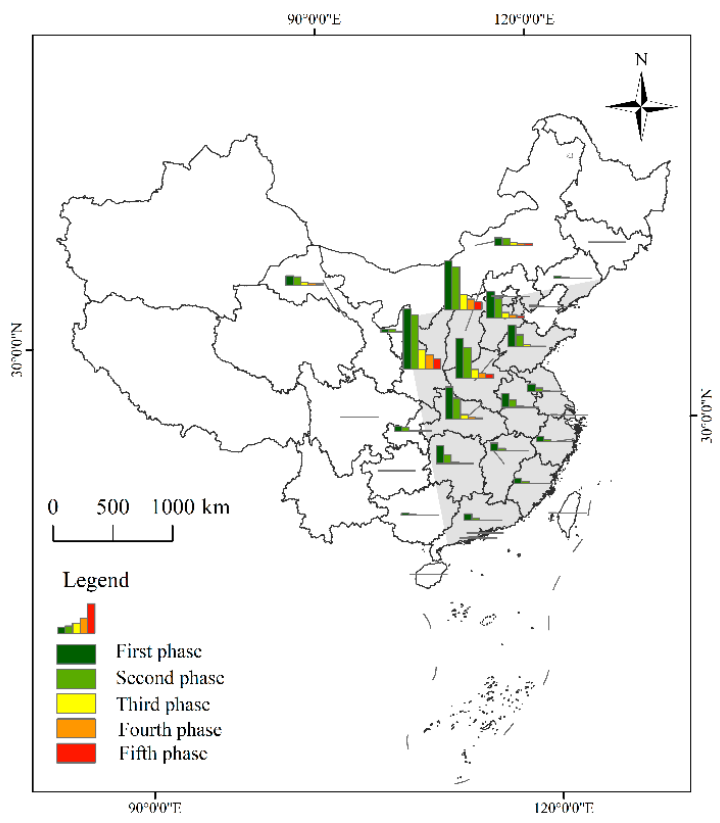

Figure 9. Dust deposition of administrative regions in China. 
In the administrative areas with influence range levels of $1-7$, the dust deposition reduction did not exceed the average dust deposition over the past 20 years. In the administrative areas with influence range levels of 8-10, the dust deposition reduction was more than that of dust deposition, and this became more obvious with increased influence distance. Taking the administrative regions in the southwestern portion of the influence range of wind break and sand fixation in the nature reserve as an example, Ningxia Hui Autonomous Region, Gansu Province and Shaanxi Province are distributed in influence range levels of 1-7 and had dust deposition reductions of $0.57,0.58$, and 0.61 times that of the past 20 years. Chongqing, Hubei, Hunan, Guangxi, Guangdong, and Hainan provinces are all distributed in influence range levels of $8-10$, and the dust deposition reductions of these regions were $1.00,1.50,2.40,3.76,3.77$, and 3.93 times the level of dust deposition over the past 20 years, respectively.

\subsection{Verification of Dust Deposition}

On the basis of the number of the days-including those with sand-dust weather days - that did not reach the secondary standard of ambient air quality in 12 cities, including Yan'an (Table 5), we can conclude that the sand-dust weather frequency is much lower than the number of days that the $\mathrm{PM}_{10}$ concentration failed to reach the secondary standard of ambient air quality.

Table 5. Particles less than 10 microns in diameter $\left(\mathrm{PM}_{10}\right)$ concentration fails to reach the secondary standard of ambient air quality and sand-dust weather days in different cities.

\begin{tabular}{|c|c|c|c|}
\hline Influence Range Level & City & $\begin{array}{l}\text { PM }_{10} \text { Concentration Failed to Reach the } \\
\text { Secondary Standard of Ambient Air Quality (d) }\end{array}$ & Sand-Dust Weather (d) \\
\hline \multirow{3}{*}{$\leq 6$} & Xi'an & 67 & 2 \\
\hline & Yan'an & 44 & 4 \\
\hline & Yulin & 42 & 8 \\
\hline \multirow{3}{*}{7} & Shiyan & 6 & 0 \\
\hline & Zhengzhou & 87 & 0 \\
\hline & Changzhi & 30 & 1 \\
\hline \multirow{3}{*}{8} & Zhangjiajie & 1 & 0 \\
\hline & Wuhan & 18 & 0 \\
\hline & Jining & 34 & 0 \\
\hline \multirow{3}{*}{$\geq 9$} & Guilin & 1 & 0 \\
\hline & Nanchang & 3 & 0 \\
\hline & Hangzhou & 4 & 0 \\
\hline
\end{tabular}

The tangible impact on various cities was analyzed based on the relationship between the ambient air quality and sand-driving wind duration. Being closer to a sand source yields a higher frequency of sand-dust weather, meaning that the air quality can be affected more easily. The frequency of sand-dust weather from March to May in 2017-2019 was highest in cities with influence range levels less than or equal to six. Although sand-dust weather occurred eight times in Yulin, the number of days that the $\mathrm{PM}_{10}$ concentration did not reach the secondary standard was less than the number of days in Xi'an and Yan'an. Among cities with influence range levels greater than six, only one sand-dust weather event occurred in Changzhi. This is not closely related to the number of days that the $\mathrm{PM}_{10}$ concentration did or did not reach the secondary standard.

We analyzed the correlations between $\mathrm{PM}_{10}$ concentrations in the specific cities and the time sequences (i.e., the current day, the next day, the third day and the fourth day) of sand-driving wind in the BNR (Table 6). Our results indicate that the correlations between $\mathrm{PM}_{10}$ concentrations and all sand-driving wind duration sequences during specific periods reach significant levels. In areas with influence range levels less than or equal to six, the correlation between $\mathrm{PM}_{10}$ concentration and sand-driving wind in Yan'an and Yulin 
reached a highly significant level, and the correlation between $\mathrm{PM}_{10}$ concentration and wind the next-day in $\mathrm{Xi}^{\prime}$ an reached a significant level. In areas with influence range levels equal to seven, the correlations between $\mathrm{PM}_{10}$ concentrations and next-day winds in Shiyan and Zhengzhou reached highly significant levels, and the correlation between $\mathrm{PM}_{10}$ concentration and next-day winds in Changzhi reached a significant level. In areas with an influence range level equal to eight, the correlation between $\mathrm{PM}_{10}$ concentration in Jining and third-day winds reached a significant level, and the correlations between the $\mathrm{PM}_{10}$ concentrations in Zhangjiajie and Wuhan and the third-day winds reached highly significant levels. In areas with an influence range level greater than or equal to nine, the correlation between $\mathrm{PM}_{10}$ concentrations in Nanchang and Hangzhou and third-day winds reached highly significant levels, and the correlation between $\mathrm{PM}_{10}$ concentration in Guilin and fourth-day winds reached a highly significant level. Therefore, we observed that the sand-driving wind duration has a hysteresis effect on the rise in $\mathrm{PM}_{10}$ concentrations. In addition, even if the sand-driving wind has ended in the nature reserve, the $\mathrm{PM}_{10}$ concentrations in cities may still increase to varying extents in the following days, leading to reduce air quality. The $\mathrm{PM}_{10}$ concentrations may also be affected by terrain and weather. For example, Shiyan City reached the Qinling Mountains in the north and Ba Mountain in the south, and the Han River and Wudang Mountain span this city, meaning that dust storms have less effect on the city. The correlation is highly significant; however, the correlation coefficient is small.

Table 6. The correlations between $\mathrm{PM}_{10}$ concentration and the time sequences of sand-driving wind.

\begin{tabular}{|c|c|c|c|c|c|}
\hline Influence Range Level & City & Current Day & Next Day & Third Day & Fourth Day \\
\hline \multirow{3}{*}{$\leq 6$} & Xi'an & 0.111 & $0.233 *$ & $0.190 *$ & 0.094 \\
\hline & Yan'an & $0.306^{* *}$ & $0.231^{* *}$ & 0.116 & 0.079 \\
\hline & Yulin & $0.318^{* *}$ & 0.073 & -0.024 & 0.071 \\
\hline \multirow{3}{*}{7} & Shiyan & -0.054 & 0.114 & $0.195 * *$ & $0.124 *$ \\
\hline & Zhengzhou & 0.116 & $0.201^{* *}$ & $0.213^{* *}$ & 0.111 \\
\hline & Changzhi & 0.102 & $0.136 *$ & 0.099 & 0.02 \\
\hline \multirow{3}{*}{8} & Zhangjiajie & -0.042 & 0.103 & $0.324^{* *}$ & $0.142 *$ \\
\hline & Wuhan & 0.007 & $0.175^{* *}$ & $0.339 * *$ & $0.164^{* *}$ \\
\hline & Jining & 0.014 & 0.112 & $0.119 *$ & 0.109 \\
\hline \multirow{3}{*}{$\geq 9$} & Guilin & 0.019 & 0.029 & $0.239 * *$ & $0.256 * *$ \\
\hline & Nanchang & -0.031 & 0.03 & $0.215 * *$ & $0.194^{* *}$ \\
\hline & Hangzhou & -0.033 & 0.027 & $0.230 * *$ & 0.134 * \\
\hline
\end{tabular}

Note: * is significant and ${ }^{* *}$ is highly significant.

\section{Discussion}

In the present study, we improved the accuracy of the influence range of wind erosion and the beneficial range of windbreak and sand fixation because we took the temporal and spatial variation rules of wind speed and the influence range of wind erosion into account. The wind speed differences at various heights and time intervals [64] rendered making predictions is very difficult [40]. In addition to this, winds from the south do not easily cause dust disasters because of their warm and humid nature, so we only considered winds from the WNW, NW, and W directions. Therefore, it is important to further improve the measurement accuracy in a follow-up study.

Medium, fine, and clay silt all have particle sizes less than $10 \mu \mathrm{m}$. Once blown up, these particles drift for a long distance at high altitudes and will be sent to the China Sea and even the North Pacific Ocean [65]. Therefore, even if there is no sand-dust weather, the $\mathrm{PM}_{10}$ concentrations will increase significantly and affect the air quality in downwind areas.

The Gobi Desert is widely distributed in the arid and extremely arid regions in north China [66]. Wind-blown sand is mainly derived from the Gobi, grasslands, and other desert belts in arid and semi-arid areas, such as the Hexi corridor and the Mongolian 
Plateau in midwestern Inner Mongolia. As a result, there are many sources of dust storms in downwind administrative regions.

Even though the $\mathrm{PM}_{10}$ concentrations in cities rapidly increased during sand-dust weather, surpassing the secondary standard of ambient air quality [67], industrial combustion, engineering construction and transportation are also sources of $\mathrm{PM}_{10}$ pollution [68-70]. As a result, the dust storms in the BNR and its surrounding areas are just one of the factors affecting cities in the influence area. $\mathrm{PM}_{10}$ is also related to weather factors and meteorological conditions in cities [71,72]. The effect of various factors on sand-dust weather must be further studied.

The benefits increasing the windbreak and sand fixation of the ecosystem in the BNR result from China's ecological policy as well as natural and economic factors. First, the Lingwu Baijitan Forest Farm, in which the reserve is located, was established in 1953 and has brought decades of experience in windbreak, sand fixation, and forestation. Second, since the BNR was designated a national nature reserve in 2000, methods such as increasing vegetation coverage and changing land use patterns have been adopted to influence ecosystem services. China's ecological protection project was implemented to promote the role of ecosystems in positive development. Ecosystem services cover production, ecological regulation, life support, and social and cultural support services as well as other types of ecosystem products. Therefore, we only discussed the effect of windbreak and sand fixation in this paper, and other ecosystem services must be further studied.

Over the past few decades, China has conducted a great deal of work in ecological protection compensation and has achieved useful results in ecological protection compensation for nature reserves [73-76]. The ecological protection compensation standard is the core of the ecological protection compensation mechanism, and ecosystem service value is one basis of this compensation standard. As one avenue of further study, we estimated the total value of ecological protection compensation on the basis of the reserve's ecological protection cost. We also proposed additional work on formulating the ecological protection compensation standard of each administrative region on the basis of the attenuation law of windbreak and sand fixation, as well as the level of social and economic development in the area. This would provide a reference for establishing ecological protection compensation systems in nature reserves.

\section{Conclusions}

The FVC of the BNR has clearly increased over the last 20 years and the area of different vegetation cover types has also changed greatly. Medium coverage accounting for $66.13 \%$ became the main type of vegetation cover up until the fifth phase. The proportion of poor coverage, low coverage, medium coverage and high coverage changed from $21.12 \%$, $75.22 \%, 3.39 \%$, and $0.27 \%$ in the first phase to $0.02 \%, 20.19 \%, 66.13 \%$, and $13.66 \%$ in the fifth phase, respectively. Poor coverage and low coverage decreased significantly, of which the reduced area was $561.79 \mathrm{~km}^{2}$, accounting for $76.13 \%$ of the total area of the BNR. The area of medium coverage and high coverage increased significantly, accounting for $62.75 \%$ and $13.39 \%$, respectively.

Only the BNR and its surrounding areas are affected by coarse sand, medium sand, fine sand and very fine sand. When the wind speed was above grade 6 , coarse silt could affect 26 downwind administrative regions, with an affected area of $2.13 \times 10^{6} \mathrm{~km}^{2}$. When the winds reached the sand-driving speed, medium silt, fine silt and clay silt could easily drift long distances in the upper atmosphere. The air quality in areas without sand-dust weather is also affected by such suspended loads. Our results indicate that windbreak and sand fixation in BNR can offer great benefits to downwind areas.

In downwind areas, the windbreak and sand fixation varied with the beneficial range, which was the distance from BNR, and the beneficial area and dust deposition decreased as the influence distance increased. Administrative regions with shorter influence distances and larger influence areas experienced greater reductions in dust deposition; thus, the benefits of windbreak and sand fixation were greater. With the gradual increase in distance, 
the dust deposition reduction gradually exceeded the dust deposition over nearly 20 years. It is observed that Shaanxi Province saw the greatest benefit of windbreak and sand fixation, with a dust deposition reduction of $4.63 \times 10^{7} \mathrm{t}$, followed by Hubei and Henan Provinces, with reductions of $4.47 \times 10^{7}$ and $4.35 \times 10^{7} \mathrm{t}$, respectively. The dust deposition reduction in 21 administrative regions was greater than the average dust deposition for the past 20 years. This indicates that establishing nature reserves effectively reduce dust deposition in downwind areas.

The temporal variation in the deposition in both administrative regions and different influence ranges tended to present a downward trend. The dust depositions in five phases were $2.04 \times 10^{7}, 1.83 \times 10^{7}, 6.63 \times 10^{6}, 4.65 \times 10^{6}$, and $3.48 \times 10^{6} \mathrm{t}$, respectively. The periodical depositions with an influence range less than or equal to 6 were $3.01 \times 10^{7}$, $2.78 \times 10^{7}, 1.05 \times 10^{7}, 7.47 \times 10^{6}$, and $5.66 \times 10^{6} \mathrm{t}$, respectively. Consequently, we can draw the conclusion that the radiating benefit of windbreak and sand fixation in the BNR prominently weakens the influence of dust weather across the entire downwind area.

The frequency of sand-dust weather is relatively high in cities near sand sources. In the 12 selected cities with various directions and sand influence ranges, the correlations between $\mathrm{PM}_{10}$ concentrations and the time sequences of sand-driving wind reach significant levels.

Author Contributions: C.S. and G.C. conceived and designed the study. C.S. collected and analyzed the data and wrote the paper. Q.Y. and R.W. made substantial contributions to the conception and design, the interpretation of data and writing of the manuscript. G.C. reviewed and edited the manuscript. All authors have read and agreed to the published version of the manuscript.

Funding: This study was supported by the National Key Research and Development Program of China: Design and assessment techniques for biodiversity conservation targets (No. 2018YFC0507200).

Institutional Review Board Statement: Not applicable.

Informed Consent Statement: Not applicable.

Data Availability Statement: Data sharing not applicable.

Conflicts of Interest: The authors declare no conflict of interest.

\section{References}

1. Reid, W.V.; Mooney, H.A.; Cropper, A.; Capistrano, D.; Carpenter, S.R.; Chopra, K.; Dasgupta, P.; Dietz, T.; Duraiappah, A.K.; Hassan, R.; et al. Millenium Ecosystem Assessment_Ecosystems and Human Well-Being: Synthesis; Island Press: Washington, DC, USA, 2005; ISBN 1597260401.

2. Daily, G.C. Nature's Services: Societal Dependence on Natural Ecosystems; Island Press: Washington, DC, USA, 1997; ISBN 1-55963476-6.

3. Xie, G.D.; Cao, S.Y.; Lu, C.X.; Zhang, C.S.; Yu, X. Current status and future trends for eco-compensation in China. J. Resour. Ecol. 2015, 6, 355-362. [CrossRef]

4. Yu, X.X.; Lu, S.W.; Jin, F.; Chen, L.H.; Rao, L.Y. The assessment of the forest ecosystem services evaluation in China. Acta Ecol. Sin. 2005, 25, 2096-2102. [CrossRef]

5. Chen, L.; Mou, Z.P.; Qin, H.P.; Su, Q. Study on ecological service function and its radiation effect of wetland ecosystem. Environ. Sci. Technol. 2017, 40, 179-186. [CrossRef]

6. Thapa, S.; Wang, L.; Koirala, A.; Shrestha, S.; Bhattarai, S.; Aye, W.N. Valuation of ecosystem services from an important wetland of Nepal: A Study from Begnas watershed system. Wetlands 2020, 40, 1071-1083. [CrossRef]

7. Cheng, L.L.; Guo, H.; Lu, Q. Review on the valuation of desert ecosystem service values. J. Desert Res. $2013,33,281-287$. [CrossRef]

8. Sawut, M.; Eziz, M.; Tiyip, T. The effects of land-use change on ecosystem service value of desert oasis: A case study in Ugan-kuqa river delta oasis, China. Can. J. Soil Sci. 2013, 93, 99-108. [CrossRef]

9. Zhao, T.Q.; Ouyang, Z.Y.; Jia, L.Q.; Zheng, H. Ecosystem services and their valuation of China grassland. Acta Ecol. Sin. 2004, 24, 1101-1110. [CrossRef]

10. Schirpke, U.; Kohler, M.; Leitinger, G.; Fontana, V.; Tasser, E.; Tappeiner, U. Future impacts of changing land-use and climate on ecosystem services of mountain grassland and their resilience. Ecosyst. Serv. 2017, 26, 79-94. [CrossRef]

11. Wang, M. Study on Evalution of Ecosystem Services in Shandong Coastal Waters; Ocean University of China: Qingdao, China, 2018. 
12. Rogers, A.D.; Frinault, B.A.V.; Barnes, D.K.A.; Bindoff, N.L.; Downie, R.; Ducklow, H.W.; Friedlaender, A.S.; Hart, T.; Hill, S.L.; Hofmann, E.E.; et al. Antarctic futures: An assessment of climate-driven changes in ecosystem structure, function, and service provisioning in the Southern Ocean. Ann. Rev. Mar. Sci. 2020, 12, 87-120. [CrossRef] [PubMed]

13. Yang, X.M. Evaluation of the Farmland Ecosystem Services in Jiangsu Province; Nanjing Agricultural University: Nanjing, China, 2011.

14. Firbank, L.; Bradbury, R.B.; McCracken, D.I.; Stoate, C. Delivering multiple ecosystem services from Enclosed Farmland in the UK. Agric. Ecosyst. Environ. 2013, 166, 65-75. [CrossRef]

15. Peng, J.; Wang, Y.L.; Chen, Y.F.; Li, W.F.; Jiang, Y.Y. Economic value of urban ecosystem services: A case study in Shenzhen. Acta Sci. Nat. Univ. Pekin. 2005, 4, 594-604. [CrossRef]

16. Larondelle, N.; Haase, D. Urban ecosystem services assessment along a rural-urban gradient: A cross-analysis of European cities. Ecol. Indic. 2013, 29, 179-190. [CrossRef]

17. Wang, Y.T.; Guo, W.H.; Liu, J.; Wang, S.J.; Wang, Q.; Wang, R.Q. Value of ecosystem services of Kunyu Mountain Natural Reserve. Acta Ecol. Sin. 2009, 29, 523-531. [CrossRef]

18. Xue, D.Y.; Bao, H.S.; Li, W.H. A valuation study on the indirect values of forest ecosystem in Changbaishan Mountain Biosphere Reserve of China. China Environ. Sci. 1999, 19, 247-252. [CrossRef]

19. Castro, A.J.; Martín-López, B.; López, E.; Plieninger, T.; Alcaraz-Segura, D.; Vaughn, C.C.; Cabello, J. Do protected areas networks ensure the supply of ecosystem services? Spatial patterns of two nature reserve systems in semi-arid Spain. Appl. Geogr. 2015, 60, 1-9. [CrossRef]

20. Badola, R.; Hussain, S.A.; Mishra, B.K.; Konthoujam, B.; Thapliyal, S.; Dhakate, P.M. An assessment of ecosystem services of Corbett Tiger Reserve, India. Environmentalist 2010, 30, 320-329. [CrossRef]

21. Wang, X.D. Comprehensive Investigation Report on Baijitan National Nature Reserve in Lingwu City of Ningxia; Ocean University of China: Qingdao, China, 2018.

22. Buitenwerf, R.; Rose, L.; Higgins, S.I. Three decades of multi-dimensional change in global leaf phenology. Nat. Clim. Chang. 2015, 5, 364-368. [CrossRef]

23. Purevdorj, T.S.; Tateishi, R.; Ishiyama, T.; Honda, Y. Relationships between percent vegetation cover and vegetation indices. Int. J. Remote Sens. 1998, 19, 3519-3535. [CrossRef]

24. Gong, G.L.; Liu, J.Y.; Shao, Q.Q.; Zhai, G. Sand-Fixing function under the change of vegetation coverage in a wind erosion area in northern China. J. Resour. Ecol. 2014, 5, 105-114. [CrossRef]

25. Xu, J.; Xiao, Y.; Xie, G.D.; Wang, Y.Y.; Zhen, L.; Zhang, C.S.; Jiang, Y. Interregional ecosystem services benefits transfer from wind erosion control measures in Inner Mongolia. Environ. Dev. 2020, 34. [CrossRef]

26. Zhang, H.Y.; Fan, J.W.; Cao, W.; Harris, W.; Li, Y.Z.; Chi, W.F.; Wang, S.Z. Response of wind erosion dynamics to climate change and human activity in Inner Mongolia, China during 1990 to 2015. Sci. Total Environ. 2018, 639, 1038-1050. [CrossRef] [PubMed]

27. Gregory, J.M.; Wilson, G.R.; Singh, U.B.; Darwish, M.M. TEAM: Integrated, process-based wind-erosion model. Environ. Model. Softw. 2004, 19, 205-215. [CrossRef]

28. Coen, G.M.; Tatarko, J.; Martin, T.C.; Cannon, K.R.; Goddard, T.W.; Sweetland, N.J. A method for using WEPS to map wind erosion risk of Alberta soils. Environ. Model. Softw. 2004, 19, 185-189. [CrossRef]

29. Xu, J.; Xiao, Y.; Xie, G.; Wang, Y.; Jiang, Y. How to guarantee the sustainability of the wind prevention and sand fixation service: An ecosystem service flow perspective. Sustainability 2018, 10, 1995. [CrossRef]

30. Zhang, H.B.; Gao, Y.; Sun, D.F. Wind erosion changes in a semi-arid sandy area, Inner Mongolia, China. Sustainability 2019, 11, 188. [CrossRef]

31. Dong, Z.B. Establishing statistic model of wind erosion on small watershed basis. Bull. Soil Water Conserv. 1988, $18,56-63$.

32. Han, Y.W.; Tuo, X.S.; Gao, J.X.; Liu, C.C.; Gao, X.T. Assessment on the sand-fixing function and its value of the vegetation in eco-function protection areas of the Lower reaches of the Heihe River. J. Nat. Resour. 2011, 26, 58-65. [CrossRef]

33. Li, B.Y. Spatial and Temporal Differences of Ecological Effects of Land Change in Yinchuan Basin; Shaanxi Normal University: Shanxi, China, 2016.

34. Ma, X.F. Ebinur Lake Wetland Landscape Pattern Change and Ecosystem Service Value Relations Research; Xinjiang Normal University: Xinjiang, China, 2017.

35. Zhu, L.K.; Southworth, J. Disentangling the Relationships between Net Primary Production and Precipitation in Southern Africa Savannas Using Satellite Observations from 1982 to 2010. Remote Sensing. Remote Sens. 2013, 5, 3803-3825. [CrossRef]

36. Ibrahim, Y.Z.; Balzter, H.; Kaduk, J.; Tucker, C.J. Land degradation assessment using residual trend analysis of GIMMS NDVI3g, soil moisture and rainfall in Sub-Saharan West Africa from 1982 to 2012. Remote Sens. 2015, 7, 5471-5494. [CrossRef]

37. Wang, J.Q. An analysis of the harmful effects on agriculture production, caused by sandstorm. J. Educ. Ist. Jilin Prov. 2010, 26, 157-158.

38. Ding, G.D. Aeolian Physics, 2nd ed.; China Forestry Publishing: Beijing, China, 2010.

39. Han, Y.W.; Tuo, X.S.; Gao, J.X.; Gao, X.T. Ecosystem services radiation of significant eco-function area in the lower reaches of Heihe River. Acta Ecol. Sin. 2010, 30, 5185-5193. [CrossRef]

40. Li, Z.S.; Zhang, Q.F.; Bao, H.J. Wind-velocity variation in recent 30 years in three typical desertified counties of north China. J. Desert Res. 2006, 26, 20-26. [CrossRef]

41. Zhan, X.L.; Han, L. Physicochemical property of aeolian sandy soil in Baijitan in Ningxia. Chin. Agric. Sci. Bull. 2015, 31, 186-190.

42. Li, J.F. Desert Climate; China Meteorological Press: Beijing, China, 2002; ISBN 9787502933890. 
43. Wu, K.N.; Zhao, R. Soil texture classification and its application in China. Acta Pedol. Sin. 2019, 56, 227-241. [CrossRef]

44. Zhou, C.L.; Yang, X.H.; Yang, F.; Huo, W.; Zhong, X.J.; Pan, H.L.; He, Q. Analysis of calculated dust emission threshold wind speed based on the field experiments. J. Arid Meteorol. 2018, 36, 90-96. [CrossRef]

45. Zhou, S.Z.; Zhang, R.Y.; Zhang, C. Meteorology and Climatology, 3rd ed.; Higher Education Press: Beijing, China, 1997; ISBN 9787040060164 .

46. Yang, Q.; Wang, T.; Chen, H.; Wang, Y.D. Characteristics of vegetation cover change in Xilin Gol League based on MODIS EVI data. Trans. Chin. Soc. Agric. Eng. 2015, 31, 191-198. [CrossRef]

47. Luo, Y.; Xu, J.H.; Yue, W.Z. Research on vegetation indices based on the remote sensing images. Ecol. Sci. 2005, 24, 75-79. [CrossRef]

48. Bao, J.Y.; Li, X.S.; Wu, B. Desertification evaluation based on sand vegetation index. J. Northeast For. Univ. 2008, 36, 69-72. [CrossRef]

49. He, Y.Q.; Qin, Y.; Fu, Q.H.; Liu, C.Q.; Yin, B. Application of mixed pixel decomposition method using dynamic endmember combination in dynamic monitoring of vegetation abundance: A case study of Changting county. Trop. Geogr. 2016, 36, 860-868. [CrossRef]

50. Li, X.S.; Gao, Z.H.; Li, Z.Y.; Bai, L.N.; Wang, B.Y. Estimation of sparse vegetation coverage in arid region based on hyperspectral mixed pixel decomposition. Chin. J. Appl. Ecol. 2010, 21, 152-158.

51. Liu, Y.; Lv, Y.H.; Zheng, H.F.; Chen, L.D. Application of regression tree in analyzing the effects of climate factors on NDVI in loess hilly area of Shaanxi Province. Chin. J. Appl. Ecol. 2010, 21, 1153-1158. [CrossRef]

52. Chen, J.J.; Huang, Y.; Zhao, X.N.; Zhang, H.Z.; Tian, Z.L. Accuracy evaluation of vegetation coverage inversion model for Alpine grassland in the source region of the Yellow River. Sci. Technol. Eng. 2019, 19, 37-45. [CrossRef]

53. Mu, S.J.; Li, J.L.; Chen, Y.Z.; Gang, C.C.; Zhou, W.; Ju, W.M. Spatial differences of variations of vegetation coverage in Inner Mongolia during 2001-2010. Acta Geogr. Sin. 2012, 67, 1255-1268. [CrossRef]

54. Wang, X.J.; Hu, E.C.; Li, A.P.; Li, Q.J. Dynamic changes of vegetation coverage in Daqingshan Nature Reserve based on MODIS NDVI image. J. Arid L. Resour. Environ. 2014, 28, 61-65.

55. Murat, A.; Zhang, X.P.; Chen, L.L.; Lin, P.F.; Sun, Y.P. Spatial-temporal distribution of desertification on the Loess plateau using the GIMMS NDVI data. Sci. Soil Water Conserv. 2015, 13, 24-31. [CrossRef]

56. Li, P.X.; Zheng, J.H.; Liu, P. Analysis of spatial and temporal variations about vegetation fractional cover in Urumqi city from 2000 to 2014. For. Resour. Manag. 2016, 88-95. [CrossRef]

57. Sha, R.N. Analysis of temporal and spatial variation of vegetation cover in Wulatehouqi based on NDVI. For. Resour. Manag. 2017, 102, 89-93. [CrossRef]

58. Sha, R.N. Spatial and Temporal Variations of Vegetation Coverage in Urad Rear Banner and Analysis of Influencing Factors; Beijing Forestry University: Beijing, China, 2018.

59. Arukhan. Temporal and spatial variation of vegetation coverage in Horqin National Nature Reserve of Inner Mongolia Based on NDVI. Inn. Mong. Sci. Technol. Econ. 2018, 50, 47-48. [CrossRef]

60. Guo, Z.C.; Liu, S.L.; Kang, W.P.; Chen, X.; Zhang, X.Q. Change trend of vegetation coverage in the Mu Us Sandy Region from 2000 to 2015. J. Desert Res. 2018, 38, 1099-1107.

61. Yan, J.Y.; Tang, Z.Y.; Yao, H.D.; Li, J.L.; Xiao, Y.G.; Chen, Y.D. A study on the air-sea fluxes exchange coefficients over the South China Sea (SCS) during the onset of southwest monsoon. Acta Meteorol. Sin. 2006, 64, 335-344. [CrossRef]

62. Zhao, C.X.; Wang, Y.Q.; Wang, Y.J.; Zhang, H.L.; Zhao, B.Q. Temporal and spatial distribution of PM2.5 and PM10 pollution status and the correlation of particulate matters and meteorological factors during winter and spring in Beijing. Environ. Sci. 2014, 35, 418-427.

63. Wang, Y.R.; Zhang, X.X.; Zhao, J.Y.; Yu, X.X.; Jiang, Q.O. Study on the response of PM2.5 and PM10 concentrations to the ground meteorological conditions in different seasons in Beijing. Environ. Monit. China 2017, 33, 34-41. [CrossRef]

64. Chen, W.N.; Dong, Z.B.; Yang, Z.T.; Han, Z.W.; Zhang, M.L.; Zhang, J.S. Threshold velocities of sand-driving wind in the Taklimakan desert. Acta Geogr. Sin. 1995, 50, 360-367.

65. Shen, W.X. Investigation on the Pollution of Airborne Inhalable Particulate Matter PM10 in Huainan City; Anhui University of Science and Technology: Huainan, China, 2007.

66. Shen, Y.C.; Wang, X.H.; Cheng, W.M.; Wu, J.F.; Lu, Q.; Feng, Y.M. Integrated physical regionalization of stony deserts in China. Prog. Geogr. 2016, 35, 57-66. [CrossRef]

67. Xu, X.Q.; Wang, X.; Huang, J.P. Observational study on the particle size distribution of sand aerosol in Zhangye and Yuzhong of Lanzhou. Plateau Meteorol. 2011, 30, 208-216. [CrossRef]

68. Bi, X.H.; Feng, Y.C.; Wu, J.H.; Wang, Y.Q.; Zhu, T. Source apportionment of PM10 in six cities of northern China. Atmos. Environ. 2007, 41, 903-912. [CrossRef]

69. Gao, S.; Pan, X.C.; Madaniyazi, L.N.; Xie, J.; He, Y.H. Preliminary study of source apportionment of PM10 and PM2.5 in three cities of China during spring. Chin. J. Prev. Med. 2013, 47, 837-842. [CrossRef]

70. Zou, B.D.; Xu, Z.Y.; Hua, L.; Han, Y.P.; Dong, S.Y.; Lu, H.F. Sources spportionment of atmospheric particles PM10 in Beijing by factor analysis. Environ. Monit. China 2007, 23, 79-85. [CrossRef]

71. Li, M.K.; Shen, Z.X.; Li, X.X.; Yao, Y.Q.; Zheng, Y.; Fan, D. Mass concentration of PM10 and its relationship with meteorological conditions over Xi'an. Chin. J. Process Eng. 2006, 6, 15-19. 
72. Xie, F.Y.; Wang, Z.F.; Wang, X.Q. A study of the characteristics of the synoptic situations and meteorological conditions in PM10 air pollution episodes of Beijing during the 2008 Olympic Games period. Clim. Environ. Res. 2010, 15, 584-594. [CrossRef]

73. Min, Q.W.; Zhen, L.; Yang, G.M. Progress of researches and practices of ecological compensation of nature reserves. J. Ecol. Rural Environ. 2007, 23, 81-84. [CrossRef]

74. Li, Y.Y. Study on construction method and implementation approaches of ecological compensation mechanism for China's nature reserves. Ecol. Environ. 2011, 20, 1957-1965. [CrossRef]

75. Wang, L.; Su, Y.; Cui, G.F. Quantitative study on the ecological compensation for nature reserves based on the "virtual land" method. J. Nat. Resour. 2011, 26, 34-47. [CrossRef]

76. Yang, Z.; Wu, J. Conservation cost of China's nature reserves and its regional distribution. J. Nat. Resour. 2019, 34, 839-852. [CrossRef] 